\title{
On passive damping in machine tool hybrid structural parts
}

\author{
Viktor Kulíšek ${ }^{1} \cdot$ Petr Kolar $^{2}$ (D) Pavel Vrba $^{2} \cdot$ Jan Smolík $^{2} \cdot$ Miroslav Janota $^{2} \cdot$ Milan Růžička $^{1} \cdot$ Martin Machálka $^{3}$
}

Received: 12 October 2020 / Accepted: 3 March 2021 / Published online: 4 April 2021

(C) The Author(s), under exclusive licence to Springer-Verlag London Ltd., part of Springer Nature 2021

\begin{abstract}
Hybrid materials combining steel or cast iron with fibre or particle composites have a good potential for lightweight machine tool structural design with high damping ratio. These materials are analyzed in the paper with a focus on damping improvement of structural components and machine tool assemblies. Fibre composites and particle composites were selected as the lightweight elements for the hybrid machine tool structure. The fibre composites were designed as low-density, high stiffness-oriented reinforcements, which were bonded to build metal structural parts conventionally. The particle composites were applied as filler materials into the hollows of the metal structural parts. Both composite structures presented a possibility to reduce the mass of the component due to the reduction of wall thickness (fibre composite) or removal of heavy ribbing (particle composites) and to influence the parts' static and dynamic stiffness. Hybrid structures, combining the light-weight elements with cast iron or welded steel, were designed and tested in case studies using experimental modal analysis methods. Experimental modal analysis was used as the main approach for identification of the damping ratio on a basic coupon level, followed by testing of structural parts in a stand-alone configuration and ending with a structural part assemblies testing. Both particle composites and fibre composites were successful in improving the damping ratio of single structural parts. However, the damping ratio of the hybrid component mounted into an assembly configuration shows only less significant improvement. The presented results demonstrate importance of the damping caused in the connecting interfaces.
\end{abstract}

Keywords Machine tool $\cdot$ Damping $\cdot$ Composites $\cdot$ Hybrid materials $\cdot$ Experimental modal analysis

\section{Introduction}

The frame structure of a machine tool plays an essential role. The frame structure consists of non-movable bodies, movable bodies, movable and non-movable structural joints, feed drives, the feed drive control and a spindle. The entire structure is responsible for machine accuracy and machining productivity under static loading caused by its own weight, dynamic loading caused by the movement of the structure,

Petr Kolar

p.kolar@rcmt.cvut.cz

1 Faculty of Mechanical Engineering, Department of Mechanics, Biomechanics and Mechatronics, Czech Technical University in Prague, Technicka 4, 16607 Prague 6, Czech Republic

2 Faculty of Mechanical Engineering, Department of Production Machines and Equipment, Research Center of Manufacturing Technology, Czech Technical University in Prague, Horska 3, 12800 Prague 2, Czech Republic

3 TAJMAC-ZPS, a.s., třída 3. Května 1180, 76302 Zlín, Malenovice, Czech Republic cutting process loading, and thermal loading from various internal and external sources. The key technical characteristics of the frame structure responding to these types of loading are static stiffness and dynamic stiffness. The dynamic stiffness depends on the static stiffness, the structural mass of the machine frame, and the damping ratio.

Since machining limits depend on the dynamic stiffness to a significant degree [1-3], improving the dynamic stiffness of a machine tool-cutting tool—workpiece assembly chain is the essential requirement for improving machining productivity. A traditional dynamic stiffness improvement scenario is based on increasing static stiffness with the aim of maintaining or reducing the mass of structural components ("lightweight design"). This can be achieved, for example, by using advanced structural optimization [4] or creating "dematerialized machine tool assembly" [5]. The key material parameters for this approach are a sufficiently high Young's modulus and shear modulus of the structural material; a low density is beneficial for the motion axis component. The optimization approach might reach several limits when traditional structural materials with excellent stiffness like steel, ductile, or cast iron are used, due to their high density. An additional improvement 


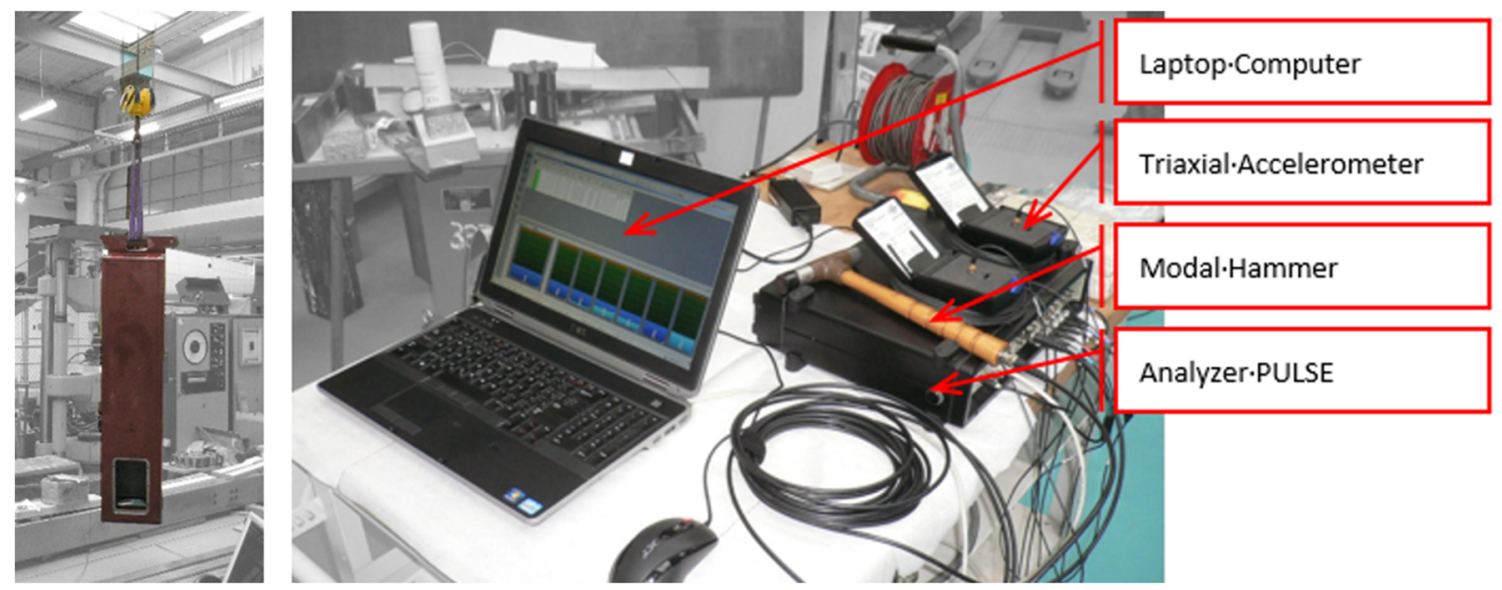

Fig. 1 Typical setup of measurement apparatus

might be possible when materials with a high Young's modulus and low density, such as engineering ceramics or fibre composites, are used [6].

Besides stiffness and density, damping is the third key factor influencing the dynamic stiffness of the frame structure. The damping capability rises due to energy losses on the microscopic interfaces inside the material structure or on the macroscopic interfaces of the structural parts. Generally, the damping of a machine tool frame is influenced mostly by the damping of connection interfaces, which are joined to the frame's structural components; the effect of the components'

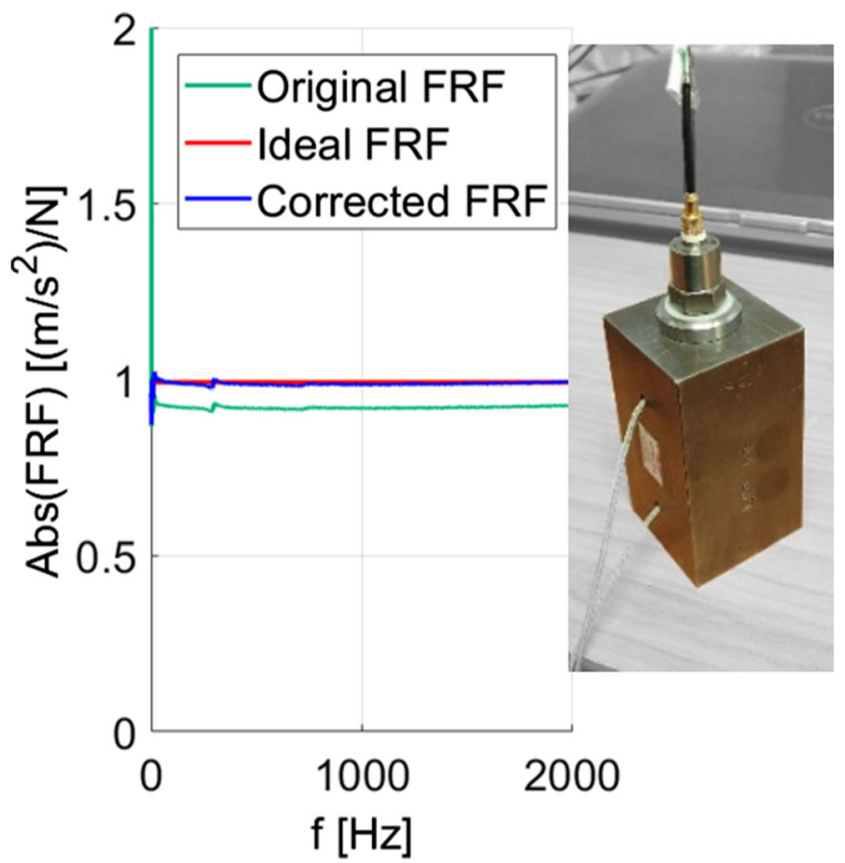

Fig. 2 Example of calibration chart for modal hammer. There is a detailed view on an accelerometer mounted on an unit mass damping on the frame damping is usually much smaller in comparison with the connection interface damping. Damping of an existing frame can be increased by passive, semi-active, or active dampers [7], which can be attached to the frame, or by specific setting of feed drive parameters [8, 9].

Application of composite structures is usually driven by a focus on lightweight design, i.e. reducing the mass of parts, while maintaining static stiffness. A high damping ratio is a secondary reason, as stated by Kroll [10]. Several scientific papers have presented applications of composite materials in production machine design with a lightweight design focus. A comprehensive overview was presented by Möhring in [6, 11], which analyzed the benefits of high stiffness, low density, high damping material applications in relation to the needs of the machine tool industry, high-capacity production and material costs, with the two latest points limiting composite material potential. Fibre composites can also result in other benefits in addition to lightweight design options with suitable stiffness behaviour. Kono presented examples of increased accuracy under thermal loading for hybrid fibre compositemetal spindles in [12].

The high price of fibre composite structures, especially in large machine tool design, may be a reason to use hybrid structures. The main idea is to combine a traditional isotropic material with a lightweight material added to specific areas of the structure. Several studies have analyzed metal-composite hybrid structures which were created through a combination of metal and fibre composite sheets. Suh [13] described a steel spindle stock with a composite coating that had 3-5 times higher damping compared to an all-steel design. Lee [14] designed a cast iron column with a glued glass fibre composite coating. The hybrid design increased damping by about $35 \%$ compared to a cast iron structure due to the shear effect in the 
Table 1 Comparison of properties of metals with a fibre composite layer. Notation: $E_{1}$ denotes the Young's modulus in direction $1 ; E_{2}$ is perpendicular to the 1 axis, which corresponds to the fibre direction for the uni-directional fibre composite; HS UD is the uni-directional layer from the high-strength carbon fibre composite; HS $[45 /-45]_{\mathrm{s}}$ is a symmetrical lay-up consisting of the angles $+45^{\circ},-45^{\circ}$ from the highstrength carbon fibre composite; UHM denotes the ultra-high modulus fibre composite.

\begin{tabular}{|c|c|c|c|c|c|}
\hline & & $\rho\left(\mathrm{kg} \mathrm{m}^{-3}\right)$ & $E_{1}(\mathrm{GPa})$ & $E_{2}(\mathrm{GPa})$ & $\mathrm{G}_{12}(\mathrm{GPa})$ \\
\hline \multirow[t]{2}{*}{ Iron-based materials } & Steel & 7850 & 210 & 210 & 80 \\
\hline & Ductile cast iron & 7050 & 169 & 169 & 66 \\
\hline \multirow[t]{4}{*}{ Carbon fibres for composite structures } & HS UD & 1550 & 139 & 5.5 & 3.8 \\
\hline & HS $[45 /-45]_{\mathrm{s}}$ & 1550 & 13.8 & 13.8 & 35.4 \\
\hline & UHM UD & 1750 & 430 & 4 & 5 \\
\hline & $\mathrm{UHM}[45 /-45]_{\mathrm{s}}$ & 1750 & 19 & 19 & 109 \\
\hline \multirow[t]{3}{*}{ Filling materials for hybrid structures } & Particle composite REC & $500 \div 700$ & $0.030 \div 0.1$ & $0.030 \div 0.1$ & \\
\hline & Particle composite GREC & $1200 \div 1700$ & $2.0 \div 4.0$ & $2.0 \div 4.0$ & \\
\hline & Aluminium foam & $180 \div 300$ & $1.0 \div 1.2$ & $1.0 \div 1.2$ & \\
\hline
\end{tabular}

glued joint. Chang [15] presented a similar application with a hybrid spindle stock. The steel structure was glued to a coating made of a unidirectional glass fibre composite with a lowstrength adhesive. The damping of the part increased about twofold. All of these applications present compromise in terms of mass reduction, stiffness and material costs in designs that achieved a higher damping ratio for single parts.

Sandwich-like structures, which combine a stiff material for the skins and a low-density material for the core, are another type of hybrid structure that has been tested for machine tools. Lee [17] described a horizontal milling machine hybrid structure composed of sandwich panels, which were made by combining fibre composites and welded steel for the skins and a honeycomb core material for the sandwich core. Compared to the original, the final design had reduced mass and higher structure damping, as the damping factor increased 1.5-5.7 times compared to the conventional structures.

Sandwich-like structures composed of metal skins and aluminium foam cores have also been tested. Neugebauer [18] presented an application of sandwich panels with an aluminium foam core and thin steel sheets for building various machine tool types with increased structural damping. Aggogeri

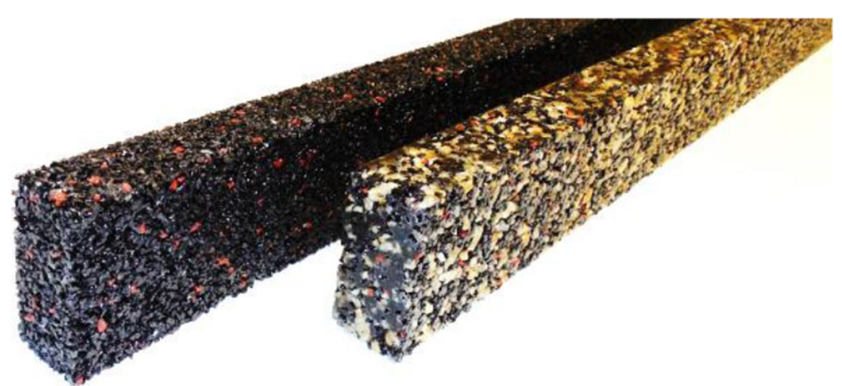

Fig. 3 Basic beams from particle composites (REC on the left, GREC on the right)
[21] presented a comparison of an aluminium foam structuremetal sandwich, fibre composite structure and traditional materials on a model structural part, in which the damping capacity of the aluminium foam sandwich part was 20-30 times higher than that of the conventional structure and the damping of the composite part was approximately 3 times higher than the conventional structure. Smolik [19, 20] applied thick aluminium foam plates to the welded structures of two columnar types of large horizontal boring machines and noted that the columnar machine with the hybrid design had a higher damping ratio. Aluminium foam sandwich structures have great potential for mass reduction due to the removal of metal ribs in structural parts, suppression of skin vibrations and high damping. On the other hand, producing these types of parts can be quite complicated. If the foam blocks are bonded into the structural part hollows, issues may arise, depending on the setting of the dimensions of the foam block and adhesive joints in the metal parts hollows, which are not machined.

Hybrid structures are also designed using materials other than metal and fibre composite skins. A composite hybrid design with a polymer concrete core and a carbon fibre composite coating was used for a lightweight milling machine design, presented by Sung-Kyum Cho [16], which resulted in $36 \%$ mass reduction and loss factor improvement. Research has also focused on the damping improvement of polymer concrete materials, which are used mostly for machine tool beds. Kepczak presented a study of additives' influence on damping of polymer concrete with broad options for damping ratio change [22].

As can be seen, several papers recommend hybrid designs of machine tool structural parts with various material combinations to improve damping ratio. However, the authors typically evaluate a particular damping ratio improvement or mass reduction. Usually, the effect of the material change is 
Table 2 Damping ratio of 2D composite and hybrid coupons

\begin{tabular}{|c|c|c|c|c|c|c|c|}
\hline Coupon & Lay-up & Material & $\begin{array}{l}\text { Thickness } \\
t_{\mathrm{WC}}(\mathrm{mm})\end{array}$ & $\begin{array}{l}\text { Thickness } \\
t_{\mathrm{WS}}(\mathrm{mm})\end{array}$ & Width $a(\mathrm{~mm})$ & $\begin{array}{l}\text { Average } \\
\text { damping } \\
\text { ratio }(\%)\end{array}$ & $\begin{array}{l}\text { Damping ratio } \\
\text { standard } \\
\text { deviation }(\%)\end{array}$ \\
\hline$\# 1$ & {$[0,45,-45,90]_{\mathrm{sym}}$} & HMC & 2.2 & & 70 & 0.23 & 0.15 \\
\hline$\# 2$ & $\begin{array}{l}{[0,45,} \\
\quad-45,90]_{2 \mathrm{sym}}\end{array}$ & HMC & 4.6 & & 70 & 0.17 & 0.13 \\
\hline \#3 & {$[0,45,-45,90]_{\mathrm{sym}}$} & HSC & 3.6 & & 70 & 0.17 & 0.05 \\
\hline \#4 & {$[0,45,-45,90]_{\mathrm{sym}}$} & $\mathrm{G}$ & 1.6 & & 70 & 0.58 & 0.18 \\
\hline$\# 5$ & {$[0]_{8}$} & $\mathrm{HMC}$ & 2.2 & & 70 & 0.41 & 0.24 \\
\hline \#6 & {$[90]_{8}$} & $\mathrm{HMC}$ & 2.2 & & 70 & 0.66 & 0.23 \\
\hline \#7 & & $\mathrm{S}$ & & 5 & 70 & 0.04 & 0.02 \\
\hline$\# 8$ & {$[0]$} & HSC & 20 & & 30 & 0.55 & 0.37 \\
\hline \#9 & {$[0]$} & UHMC & 20 & & 30 & 0.47 & 0.20 \\
\hline$\# 10$ & {$[0]$} & UHMC & 20 & & 30 & 0.49 & 0.21 \\
\hline$\# 1 \mathrm{HA}$ & {$[0,45,-45,90]_{\mathrm{s}}$} & $\mathrm{HMC}+\mathrm{S}$ & 2.2 & 5 & 70 & 0.25 & 0.13 \\
\hline \#1HB & {$[0,45,-45,90]_{\mathrm{s}}$} & $\mathrm{HMC}+\mathrm{S}$ & 2.2 & 8 & 70 & 0.26 & 0.16 \\
\hline$\# 1 \mathrm{HC}$ & {$[0,45,-45,90]_{\mathrm{s}}$} & $\mathrm{HMC}+\mathrm{S}$ & 2.2 & 3 & 70 & 0.31 & 0.19 \\
\hline$\# 2 \mathrm{H}$ & {$[0,45,-45,90]_{2 \mathrm{~s}}$} & $\mathrm{HMC}+\mathrm{S}$ & 4.6 & 5 & 70 & 0.24 & 0.09 \\
\hline$\# 3 \mathrm{H}$ & {$[0,45,-45,90]_{\mathrm{s}}$} & $\mathrm{HSC}+\mathrm{S}$ & 3.6 & 5 & 70 & 0.20 & 0.12 \\
\hline \#4H & {$[0,45,-45,90]_{\mathrm{s}}$} & $\mathrm{G}+\mathrm{S}$ & 1.6 & 5 & 70 & 0.38 & 0.27 \\
\hline$\# 5 \mathrm{H}$ & {$[0]_{8}$} & $\mathrm{HMC}+\mathrm{S}$ & 2.2 & 5 & 70 & 0.20 & 0.11 \\
\hline$\# 6 \mathrm{H}$ & {$[90]_{8}$} & $\mathrm{HMC}+\mathrm{S}$ & 2.2 & 5 & 70 & 0.33 & 0.28 \\
\hline \#9H & {$[0]$} & UHMC & 20 & 2 & 30 & 0.42 & 0.30 \\
\hline
\end{tabular}

Abbreviations used: HMC high-modulus carbon fibres (Young's modulus of fibre $390 \mathrm{GPa}$ ), HSC high-strength carbon fibres (Young's modulus of fibre $230 \mathrm{GPa}$ ), UHMC ultra-high-modulus carbon fibres (Young's modulus of fibre $780 \mathrm{GPa}$ ), $G$ glass fibres (Young's modulus of fibre $74 \mathrm{GPa}$ ), $S$ steel structure

described on a single component, on which the damping improvement is demonstrated. The influence of material damping and especially connection interface damping, along with lightweight design benefits in structural parts assembly, is not dealt with separately nor described. Therefore, it is not easy to compare the presented data and deduce general rules for selection of an appropriate hybrid design solution and evaluate the efficiency of application of new material structures.

Recently, there has been a large research focus on using finite element-based methods on a prediction of machine tool dynamic behaviour with focus on the damping effect of machine tool and its components. Publications by Zaeh and Semm [36-40] and Brecher [41] are focused on modelling i)

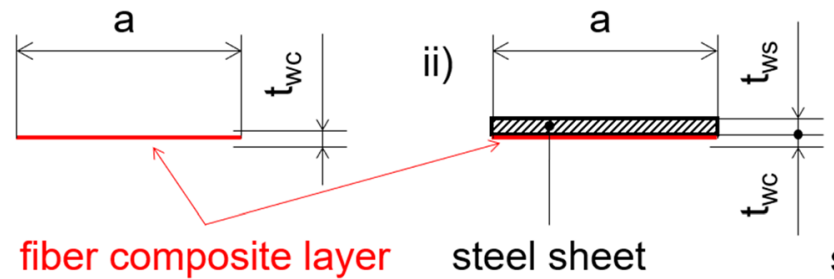

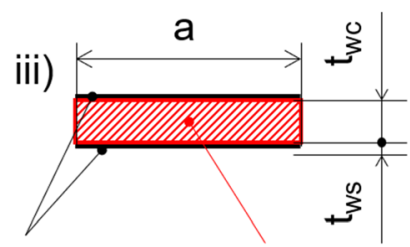

steel plate fiber composite layer

Fig. 4 Cross sections of 2D coupons: (i) fibre composite coupon; (ii) hybrid coupon \#1H-\#6H; (iii) hybrid coupon \#9H. Nomenclature: twc: carbon fibre composite sheet thickness; tws: steel sheet wall thickness 

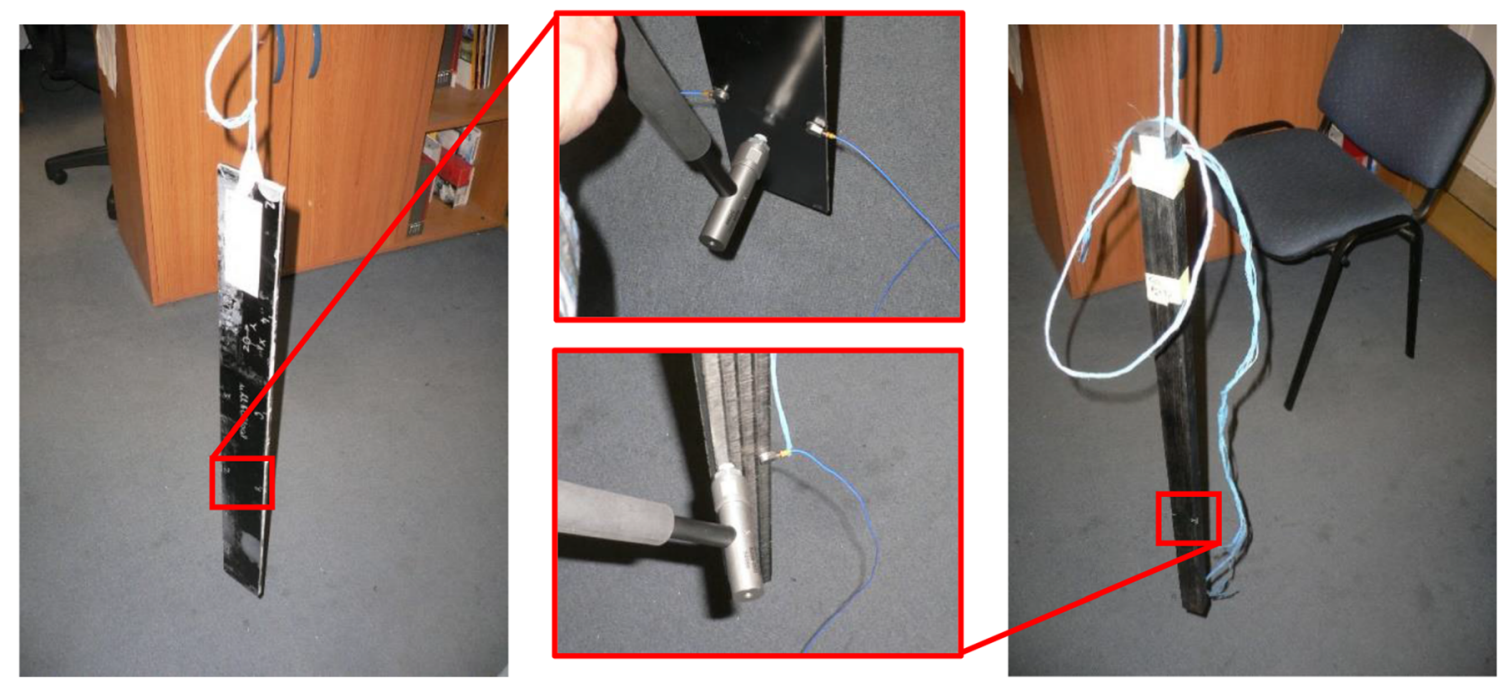

Fig. 5 Experimental modal analysis of 2D composite coupons (coupons \#1-\#7 on the left, \#8-\#10 on the right)

of machine tool behaviour using linear damping and nonlinear friction effects, using the local damping effects of machine tool structural parts, connection interfaces, and motion mechanism like ball-screw drives. The methods usually use experimental approaches to identify damping ratios of the interfaces and develop certain approaches how to implement the values into the global damping matrix of the machine tools. Successful application of those methods would help in evaluation of the composite or hybrid application efficiency on the machine tool dynamic behaviour improvement as long as the experimental data for the composite-hybrid structures are available.

The goal of this paper is to study and compare the damping ratio values of various types of basic hybrid structures at three levels: material coupon, structural part and structural assembly. The study aims to present the damping potential of various additional materials to increase total structural damping and decrease dynamic compliance. As the main tool for this research, experimental modal analysis methods were used.

\section{Modal parameters measurement and damping evaluation}

Main modal parameters are damped natural frequency $f_{d}$, damping ratio $\zeta$ and modal vector (or mode shape) $V$. Modal parameters have key importance in description of machine tool vibration and are widely used throughout technical community in this area of research and development [28-35]. There are two approaches how to obtain modal parameters. First is analytical way and second is experimental one. Analytical approach has one important deficiency. It is not possible to get damping ratio using predictive simulation analysis. This is the main reason why Experimental Modal Analysis (EMA) was used in this study as a main approach. EMA was used for experimental evaluation of the damping ratio of the material coupons and the machine structures, respectively. For all the experiments, a B\&K PULSE analyzer was used for data collection. A modal hammer was used for excitation of the measured structures. A one-axial or a three-
Table 3 Comparison of modal properties for profile coupons with fibre composites

\begin{tabular}{|c|c|c|c|c|c|c|}
\hline \multirow[t]{2}{*}{ Mode } & \multicolumn{2}{|l|}{ Steel only } & \multicolumn{2}{|c|}{ Composite only } & \multicolumn{2}{|c|}{ Hybrid structure (bonded steel+composite) } \\
\hline & $f(\mathrm{~Hz})$ & $\zeta(\%)$ & $f(\mathrm{~Hz})$ & $\zeta(\%)$ & $f(\mathrm{~Hz})$ & $\zeta(\%)$ \\
\hline 1 & 384 & 0.04 & 158 & 0.38 & 424 & 0.25 \\
\hline 2 & 601 & 0.03 & 180 & 0.34 & 435 & 0.24 \\
\hline 3 & 610 & 0.03 & 278 & 0.36 & 710 & 0.19 \\
\hline 4 & 653 & 0.03 & 311 & 0.28 & 729 & 0.29 \\
\hline 5 & 706 & 0.03 & 342 & 0.28 & 738 & 0.19 \\
\hline \multicolumn{2}{|c|}{ Average damping ratio } & 0.04 & & 0.33 & & 0.16 \\
\hline \multicolumn{2}{|c|}{ Damping of 1 st bending mode } & 0.06 & & 0.51 & & 0.12 \\
\hline
\end{tabular}




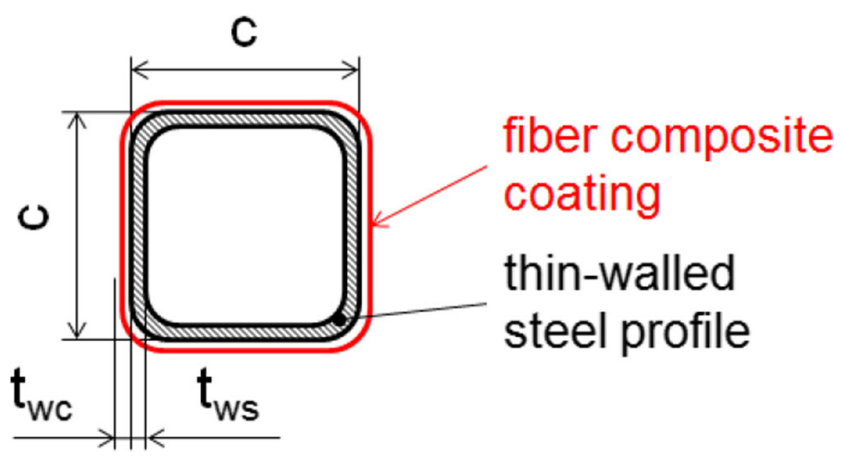

Fig. 6 Cross-section of hybrid fibre composite-steel profile

axial accelerometer was used for vibration response measurement. The weight of the modal hammer and accelerometer was selected according to the size and weight of the measured coupon or structure. The modal parameters were estimated from the measured data after the experiments had been performed. The modal parameters are as follows: natural frequency, damping ratio and mode shape. For the cases where the frequency response functions of dynamic compliance were measured, the maximum absolute compliance value was also evaluated.

Measurement setup is as follows. First, both acceleration (from an accelerometer) and force (from modal hammer) signals are obtained. Then, the frequency response function $(\mathrm{FRF})$ in form of accelerance $\left(\left(\mathrm{m} / \mathrm{s}^{2}\right) / \mathrm{N}\right)$ is calculated. The final step is double integration of the FRF into form of dynamic compliance $(\mathrm{m} / \mathrm{N})$. The reason of double integration is that dynamic compliance has close relationship with most engineering applications concerning machine tool. The best example is theory of chatter. An example of typical setup of measurement apparatus is shown in Fig. 1.
Calibration setup of measurement apparatus was as follows. First, the accelerometers were calibrated with B\&K 4294 calibration exciter. The second step was to calibrate modal hammer by measuring FRF on unit mass. The calibration curve is shown in Fig. 2. This procedure was performed before each measurement.

The damping ratio was evaluated using the following methods: Least Squares Exponential (LSCE), Rational Fraction Polynomial Method (RFP) and Complex Mode Indicator Function (CMIF). For detailed description, see [23-25]. In an ideal case, the methods should lead to similar results, but for variable conditions (low damping, rigid body modes, etc.) each method may yield different results. In this study, a combination of three methods was used to eliminate possible damping estimation errors on the coupons. The results presented in this paper were chosen from the evaluation and the methods were selectively used to ensure that the optimal method was used for the specific conditions of the experiments.

The LSCE method was the best option for very low damping coupons because it works in the time domain. For higher damping values or closed modes, it was better to use the RFP method as it works in the frequency domain and in frequency cut-out. The CMIF method was chosen when mode shapes had to be estimated because this method works well for multiple reference sensors.

The experiment boundary conditions have a crucial influence on the modal parameters and a particularly large influence on the damping ratio [26, 27]. To minimize the influence of boundary condition effects, the structural parts or large material coupons were supported at the nodal points of the first bending modes using compliant metal springs or other compliant supports. The smaller
Fig. 7 Hybrid fibre compositesteel profile coupon. The white point shows the excitation and response measurement place. The detail on the right presents direction the excitation and response measurement

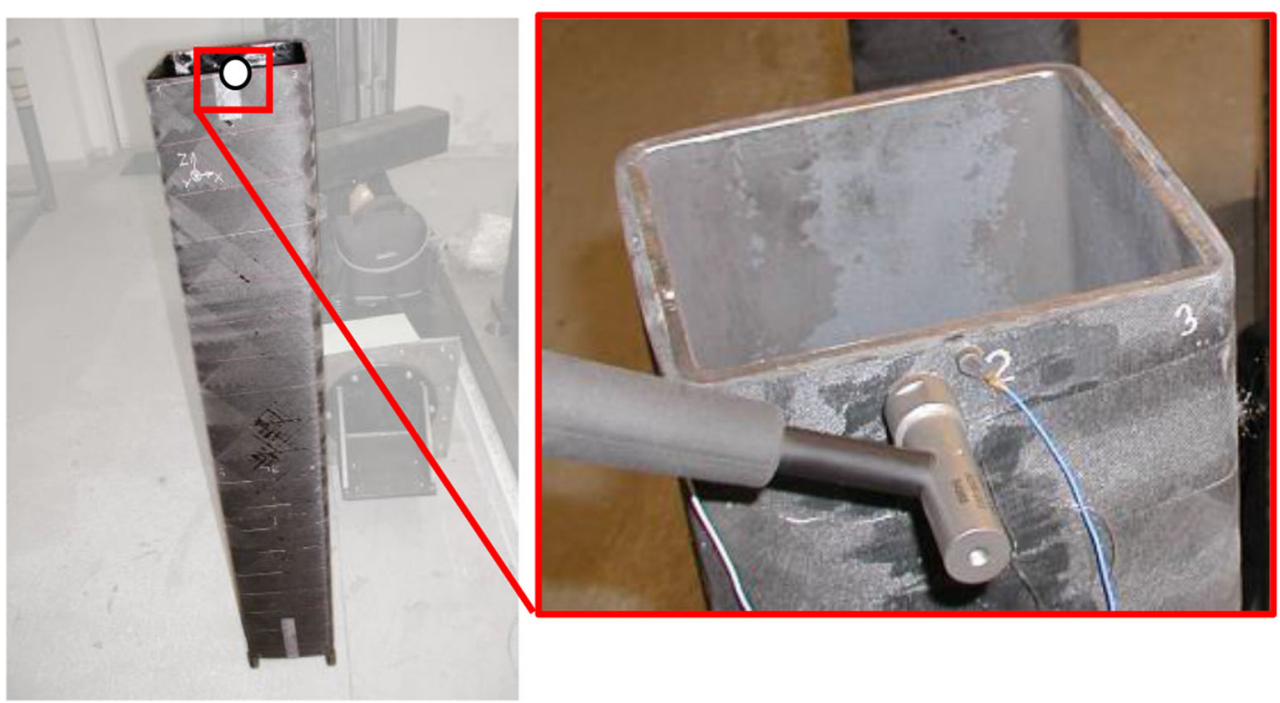




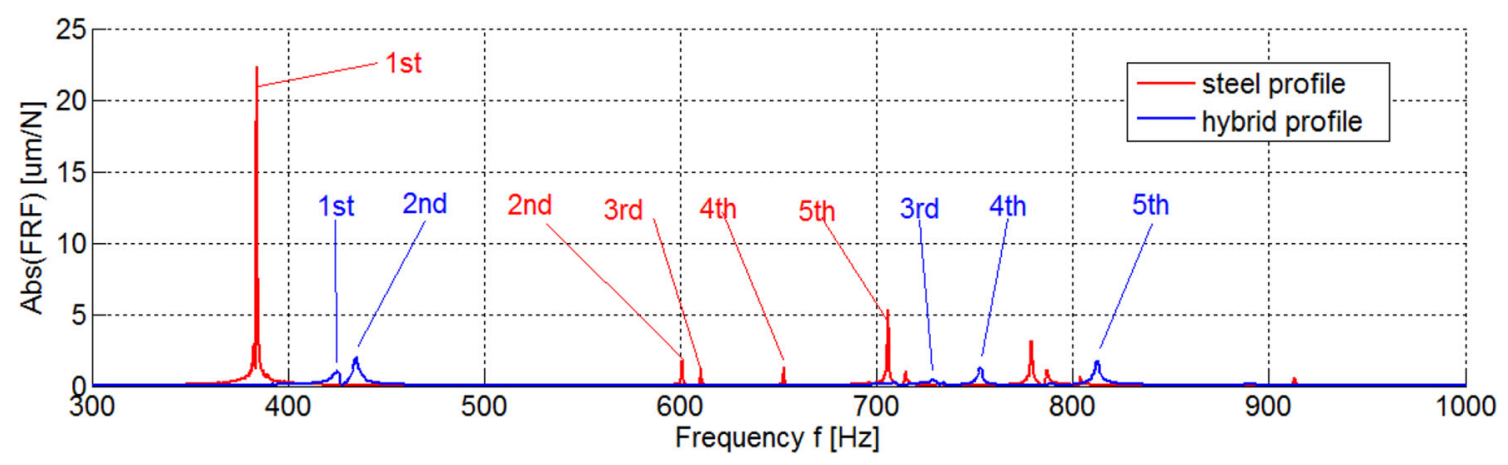

Fig. 8 Dynamic compliance-frequency transfer function-comparison of steel and hybrid fibre-composite-steel profile behaviour

level 2D and 3D material structure coupons were fixed on a long compliant suspension during the measurements (see Fig. 5, for example). For no fixation points, the coupons were placed on the coil springs. The excitation and response measurement were on the free end of the coupon. The final damping ratio was computed as the average value of the damping ratio identified for the specified number of compliant body Eigenfrequencies. This approach neglected damping variations due to the local influence of the coupon seating (i.e. rigid body modes).

Due to the wide variety of coupons and parts tested in the study, it was impossible to maintain the same boundary conditions during all the experiments. However, in each of the tested groups, which were directly comparable, the boundary conditions were set equally and the results are directly comparable. Therefore, it was possible to directly evaluate the improvement, i.e. the change in the damping ratio between the hybrid structures and the traditional metal designs.

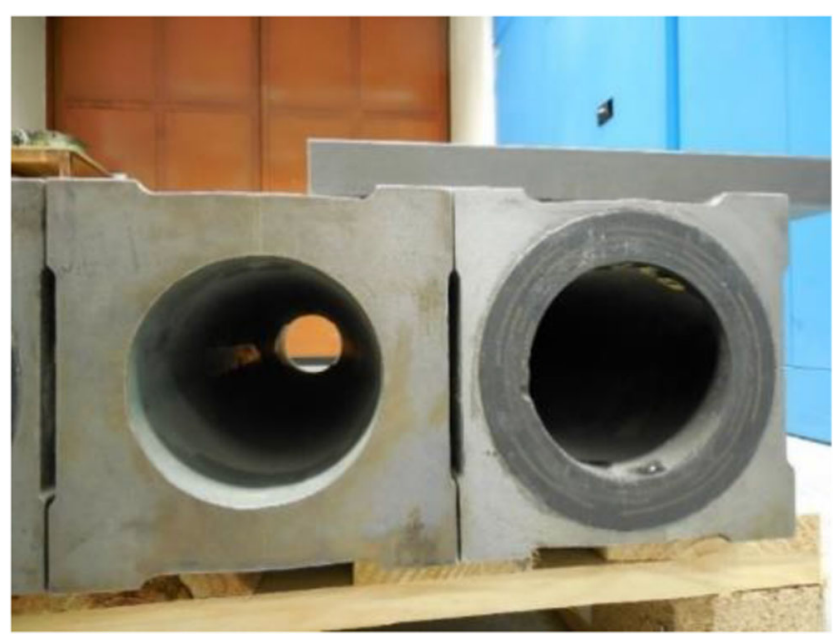

Fig. 9 Model hybrid spindle ram-reference cast iron ram (left), hybrid ram with reduced metal wall thickness and reinforcing composite tube (right)

\section{Introduction on materials used for increasing the structural damping}

Materials with high damping potential for machine tool structural part design were selected for the analysis of potential damping improvement. Two groups were used for damping improvement evaluation:

- Hybrid structures based on structural layers of fibre composites and metals

- Hybrid structures based on structural metals with particle composite reinforcement

\subsection{Fibre composites for hybrid structures}

The first material group for hybrid structures was a combination of fibre composites and metals; both materials significantly influence hybrid structure stiffness and mass. The hybrid structures benefit from the great directional stiffness, damping and low density of the fibre composites, along with the good stiffness of the isotropic metals. Compared to designs which use only fibre composites, the metals introduce further benefits, e.g. the option of making connection interfaces on the metal part and using standard machine tool structural part designs and manufacturing methods. The entire hybrid structure can be conceived as a lightweight design, where the mass of the hybrid structure is reduced in comparison with the reference all-metal design due to the reduced amount of metal material replaced by the composite. Or it can be designed as a reinforced design, where the composite is added to improve static or dynamic stiffness at the cost of a small mass increase.

Fibre composite materials comprise a large group, as they differ by fibre or matrix type or fibre orientation. For machine tool applications, only fibre composites which have a Young's modulus stiffness similar to steel, cast iron or in the worst case, aluminium, should be used as a material replacement. To use materials with lower stiffness parameters, the 
Table 4 Properties of model hybrid spindle rams with fibre composites (see Fig. 13 for vertical/horizontal orientation)

\begin{tabular}{lllllll}
\hline & Mass (kg) & $\begin{array}{l}\text { Number of } \\
\text { rubber layers (-) }\end{array}$ & $\begin{array}{l}\text { Stiffness- } \\
\text { horizontal (N/um) }\end{array}$ & $\begin{array}{l}\text { Stiffness- } \\
\text { horizontal (\%) }\end{array}$ & $\begin{array}{l}\text { Stiffness- } \\
\text { vertical (N/um) }\end{array}$ & $\begin{array}{l}\text { Stiffness- } \\
\text { vertical (\%) }\end{array}$ \\
\hline Cast iron ram & 142.5 & N/A & 16.4 & $100 \%$ & 20.4 & $100 \%$ \\
Hybrid ram \#1 & 104.0 & 0 & 17.4 & $106 \%$ & 23.0 & $113 \%$ \\
Hybrid ram \#2 & 104.0 & 3 & 15.2 & $93 \%$ & 20.1 & $99 \%$ \\
Hybrid ram \#3 & 103.5 & 4 & $88 \%$ & 18.6 & $91 \%$ \\
\hline
\end{tabular}

components would have to be designed with a larger volume of the structural material and the weight reduction would be neglected. For machine tool structural components, this is valid mainly due to their loading, which consists of bending and torque.

Therefore, high-strength or high-modulus carbon fibres were selected as the most suitable fibre types for the present study. Standard high-strength carbon fibres have a Young's modulus of approximately $230 \mathrm{GPa}$ in the fibre direction and a density of approximately $1800 \mathrm{~kg} \mathrm{~m}^{-3}$, while commercially available high-modulus fibres have a Young's modulus up to 800-900 GPa in the fibre direction and a density of approximately $2100 \mathrm{~kg} \mathrm{~m}^{-3}$.

The mechanical properties of fibres are reduced in the final product, which is a cured unidirectional composite consisting of fibres and a matrix. The typical properties for high-strength carbon fibre-epoxy layers (HS) and (ultra)-high modulus carbon fibre-epoxy layers (UHM) are shown in Table 1 for two types of orientation which give the best stiffness: $0^{\circ}$ fibre orientation (UD) for tension-compression and bending, and symmetrical $\pm 45^{\circ}$ fibre orientation for torsion. The properties, given in Table 1, were derived for the composite with fibre volume fraction $60 \%$.

\subsection{Particle fillers for hybrid structures}

The other material group was developed as a combination of structural metals and filler materials. In the design, structural stiffness is provided by a traditional metal (iron or cast iron) and the filler material merely supports the part walls and distributes the loading between the walls. In general, lightweight materials like porous foam structures, reduced density concrete and aluminium honeycomb cores can be used as fillers. In this study, particle composites were used as filler materials.

Fig. 10 Boundary conditions for model hybrid ram stand-alone testing. Detail of the excitation and response measurement on the right
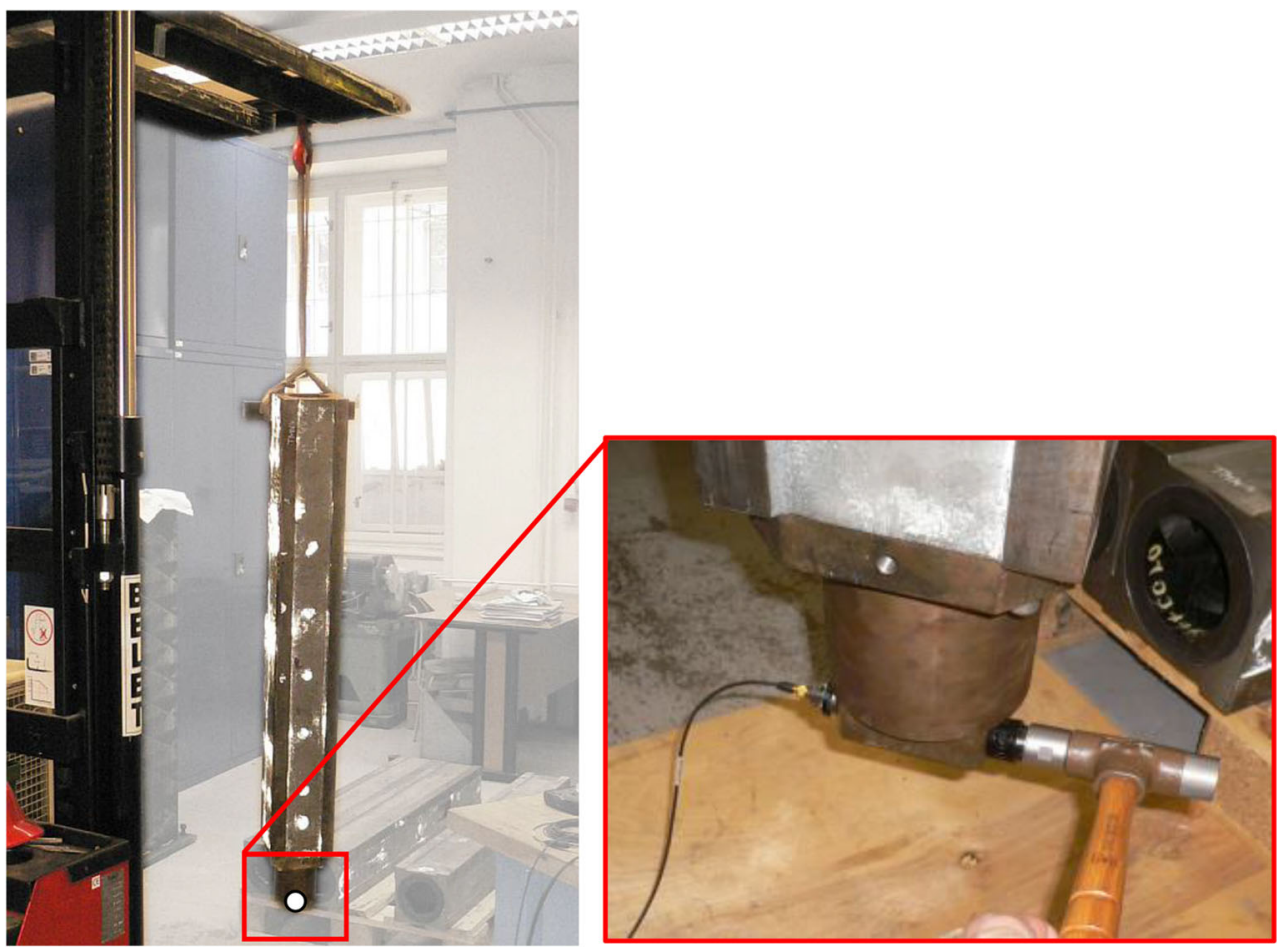


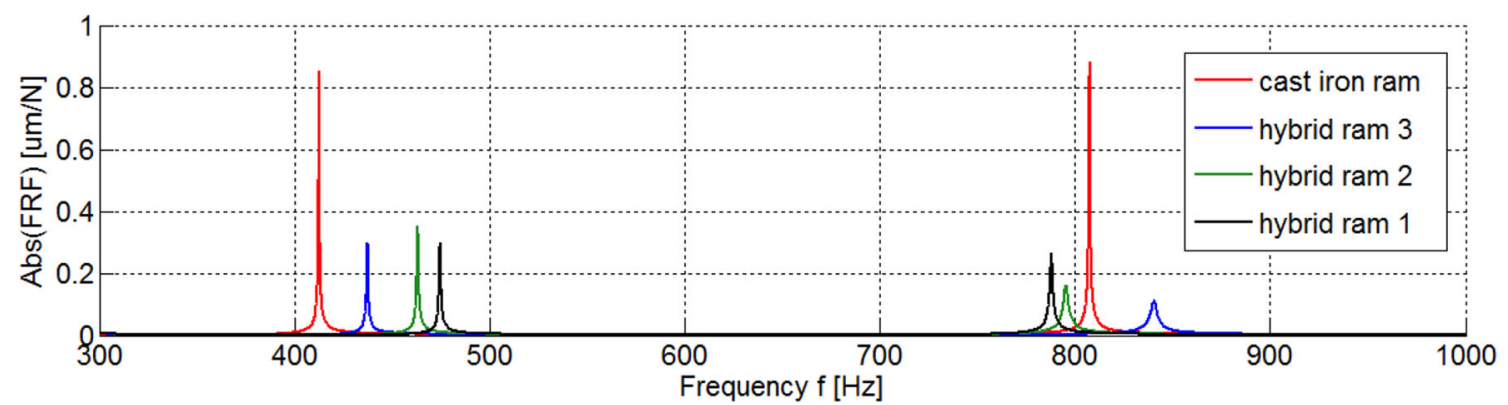

Fig. 11 Comparison of dynamic compliance of the stand-alone rams

This type of hybrid structure, if correctly applied, helps suppress structural part skin vibrations and enables the designer to remove the ribs in the structural part design. This can either reduce the part weight or if the removed material is used for structural skin reinforcement, it can lead to a new design with enhanced stiffness properties with a slightly higher weight due to the filler material.

Particle composites were selected as the filler materials for the study. The particle composites were based on particles (stone, rubber), which were held together by an epoxy resin. Two mixtures were prepared. The first one is denoted as REC (rubber epoxy compound). The mixture mass consists of $13 \%$ epoxy and $87 \%$ milled rubber. The other mixture was denoted as GREC (grit rubber epoxy compound). The mixture mass consists of $16 \%$ epoxy, $50 \%$ stones and $34 \%$ milled rubber. The REC mixture was composed as a lightweight mixture with high damping potential due to the presence of rubber particles. The GREC mixture was composed as a stiffer filler material, which combines stiffness and damping with the cost of higher added weight. The particle composite structure is shown in Fig. 3. The aim of these mixtures was to prepare a lightweight filler material to fill the hollows of machine tool structural parts with the benefits of static stiffness and increased damping. The nominal material properties are given in Table 1. Aluminium foam is included for comparison, as this filler material had been successfully used in several previous research studies $[19,20]$. The main advantage of the particle composite mixtures is that they pour easily into the internal space of the structure.

\section{Hybrid structures based on fibre composites}

In this section, the damping properties of the hybrid structures based on fibre composites and iron-based materials are experimentally analyzed. The effect of the added fibre composite reinforcement was evaluated in several steps. Firstly, the elementary fibre composite material coupons were tested (see Section 4.1). The influence on fibre type, orientation and other lay-up parameters was observed and is discussed for both the composite coupons and the hybrid coupons. Secondly, largescale hybrid composite coupons were tested (see Section 4.2). The damping ratios of the steel structure, composite structure and joint hybrid structure are compared. The last step focused on the structural part. Examples of a spindle ram with a thickwalled outer body made of ductile cast iron and inner composite reinforcement were tested in a stand-alone configuration and in an assembly configuration. The damping ratio changes observed in all of the experimental data are discussed in Section 4.4.

\subsection{Damping of 2D beam coupons from fibre composites}

A basic comparison of the damping properties of fibre composites and the hybrid fibre composite + metal structures was performed on flat beam coupons (noted as $2 \mathrm{D}$ coupons). 2D composite coupons \#1-\#7 were made as thin-walled beams with a length of $700 \mathrm{~mm}$ and a cross section of $a=70 \mathrm{~mm}$ and various wall thicknesses. They were made of composite

Table 5 Comparison of frequencies, damping ratio and dynamic compliance for stand-alone measurements of spindle rams

\begin{tabular}{lllllllll}
\hline & $f_{1}(\mathrm{~Hz})$ & $\zeta_{1}(\%)$ & $\left|\mathrm{H}_{1}\right|(\mu \mathrm{m} / \mathrm{N})$ & $f_{2}(\mathrm{~Hz})$ & $\zeta_{2}(\%)$ & $\left|\mathrm{H}_{2}\right|(\mu \mathrm{m} / \mathrm{N})$ & $\zeta_{1-5}(\%)$ & Damping comparison \\
\hline Cast Iron & 412.6 & 0.03 & 0.9 & 807.4 & 0.03 & 1.3 & 0.04 & $100 \%$ \\
Hybrid \#1 & 474.7 & 0.06 & 0.3 & 788.0 & 0.07 & 0.4 & 0.08 & $200 \%$ \\
Hybrid \#2 & 463.2 & 0.06 & 0.4 & 795.4 & 0.14 & 0.2 & 0.12 & $300 \%$ \\
Hybrid \#3 & 437.5 & 0.07 & 0.3 & 840.5 & 0.18 & 0.2 & 0.13 & $325 \%$ \\
\hline
\end{tabular}




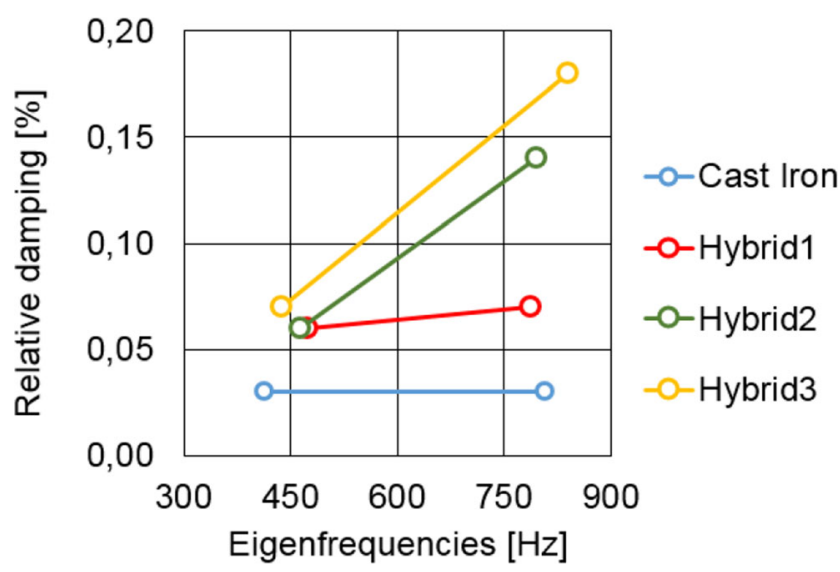

Fig. 12 Comparison of relative damping on the first second frequency for various stand-alone ram coupons

prepregs with epoxy resin, using high-strength carbon fibres (HSC), high-modulus carbon fibres (HMC) or glass fibres. Coupons \#8, \#9 and \#10 were made as thick-walled beams with a cross-section of $30 \times 20 \mathrm{~mm}$ and a length of $700 \mathrm{~mm}$ using high-strength carbon fibres or ultra-high-modulus carbon fibres. After the initial experimental modal analysis measurements, the hybrid coupons were created by bonding a steel sheet to the composite coupons. The joint between the composite and steel was made with an epoxy based adhesive. The coupon sketch is shown in Fig. 4 and the basic specification of coupons is given in Table 2 .

The measurement using experimental modal analysis was performed with coupon fixation via a flexible rope (see Fig. 5) and the dynamic behaviour of the coupons was evaluated. The average damping ratios are shown in Table 2. The average damping ratio and the standard deviation were calculated from the first nine non-rigid body modes for composite specimens.

The conversion from the composite coupons to the hybrid coupons was done using steel plates of thickness $t_{w s}=3 ; 5 ; 8$ $\mathrm{mm}$. The composite plate was bonded onto one side of steel using an epoxy adhesive joint of 0.2-mm thickness. The comparison of the hybrid fibre composite coupon results is given in Table 2. The average damping ratio was calculated from the first seven non-rigid body modes.
The results shown in Table 2 demonstrate how the different composite lay-ups influence damping. Depending on the layer orientation, the average damping ratio for the high-modulus fibres ranged from 0.10 to $0.58 \%$. The lowest value was obtained for a combined orientation of fibres in $0, \pm 45$ and $90^{\circ}$, which corresponds to a lay-up with quasi-isotropic in-plane laminate properties. The highest damping was obtained for a coupon with transverse fibre orientation only $\left(90^{\circ}\right)$, which had the highest bending compliance in the coupon batch. The coupons with $0^{\circ}$ fibre orientation, i.e. coupons with the highest tensile or bending stiffness, had an average damping ratio in the range of $0.30-0.40 \%$, i.e. in the upper range of the values.

The results also indicated that the damping ratio for the composite coupons depends on thickness. The damping ratios of the high-modulus and the high-strength carbon fibres are almost similar, while the coupons from the glass fibres had significantly higher damping. All composite coupons had significantly higher average damping than the steel coupon (damping ratio $\zeta=0.01 \%$ ).

The average damping ratio of the hybrid fibre composite coupons was in the range of $0.20-0.32 \%$. The values were still significantly higher than the damping of the steel beam, but the effect of different fibre types or fibre orientation was minimized as the variation of the average ratio was smaller in comparison with the previously tested fibre composite coupons. The influence of steel thickness variation on the damping ratio was marginal. Therefore, the fibre compositemetal hybrid structure offers damping improvement with the option of stiffness reinforcement of the all-metal design. The results demonstrate that hybrid structure damping is marginally influenced by fibre layer orientation. Therefore, the coupon test showed that it is possible to optimize fibre orientation to obtain the best structural part stiffness without significantly influencing hybrid part damping.

\subsection{Damping of profile (3D) hybrid coupons}

This group of elementary material coupons comprised hybrid structures which combine a steel profile with a composite outer reinforcement (see Fig. 6). The coupons with fibre

Table 6 Comparison of frequencies, damping ratio and dynamic compliance for spindle rams in assembly measurement

\begin{tabular}{lllllllll}
\hline & $f_{1}(\mathrm{~Hz})$ & $\zeta_{1}(\%)$ & $\left|\mathrm{H}_{1}\right|(\mu \mathrm{m} / \mathrm{N})$ & $f_{2}(\mathrm{~Hz})$ & $\zeta_{2}(\%)$ & $\left|\mathrm{H}_{2}\right|(\mu \mathrm{m} / \mathrm{N})$ & $\zeta_{1-5}(\%)$ & $\zeta_{1-5}$ comparison \\
\hline Cast iron & 61.8 & 6.40 & 0.47 & 72.4 & 3.35 & 0.87 & 4.88 & $100 \%$ \\
Hybrid \#1 & 63.5 & 5.36 & 0.63 & 73.2 & 2.76 & 0.93 & 4.10 & $84 \%$ \\
Hybrid \#2 & 63.7 & 5.21 & 0.78 & 70.3 & 3.19 & 1.0 & 4.2 & $86 \%$ \\
Hybrid \#3 & 60.8 & 5.02 & 0.79 & 72.4 & 3.35 & 0.99 & 4.2 & $86 \%$ \\
\hline
\end{tabular}




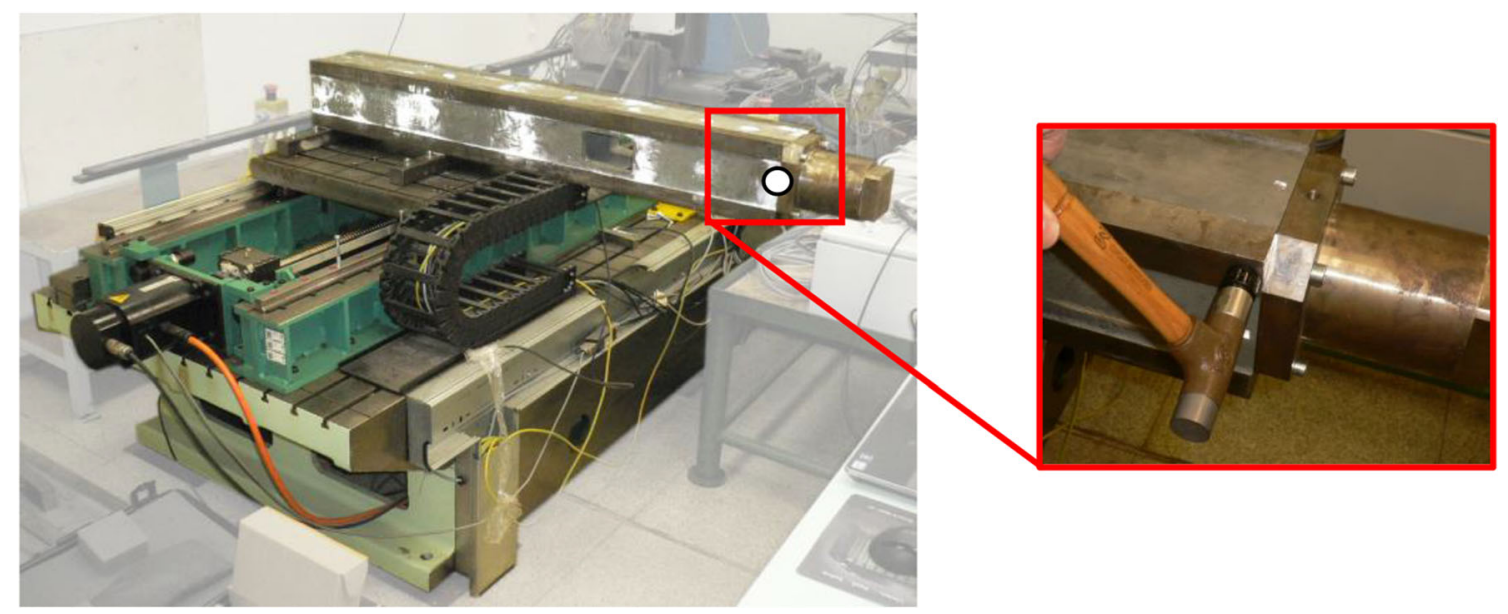

Fig. 13 Configuration of ram testing in the assembly stand

composites had a length of $1000 \mathrm{~mm}$, and a steel square profile with a wall width of $150 \mathrm{~mm}$ and a wall thickness of $5 \mathrm{~mm}$ was used. The composite reinforcement, which was bonded to the profile, had a thickness of $5 \mathrm{~mm}$. For the analysis, the hybrid reinforced coupons were placed on springs (see Fig. 7). The modal properties and damping ratios for the fibre composite base structures are given in Table 3 . The effect of the layer of composite material added to the steel profile is demonstrated in Fig. 8, where the dynamic responses of the coupons are shown.

The application confirmed the potential of hybrid steelcomposite structures. The basic steel structure was reinforced by bonded composite layers. The average damping ratio improved from 0.03 to $0.16 \%$. The Eigenfrequencies increased as well. The dynamic compliance decreased. To achieve these improved results, the steel profile with a mass of $22 \mathrm{~kg}$ was converted into the hybrid structure by adding $3.5 \mathrm{~kg}$ of composite reinforcements.

\subsection{Spindle ram based on ductile cast iron body with inner fibre composite reinforcement}

A model ductile cast iron spindle ram was made of cast iron with a cross-section of $170 \mathrm{~mm}$ by $170 \mathrm{~mm}$ and a length of $1170 \mathrm{~mm}$ (see Fig. 9). The reference ram was compared with three hybrid spindle ram designs with similar static stiffness. The hybrid rams were designed using a composite tube reinforcement, which was bonded into the inner space of the ram. For the lightweight design options, the ductile cast iron wall thickness was reduced without changing the external
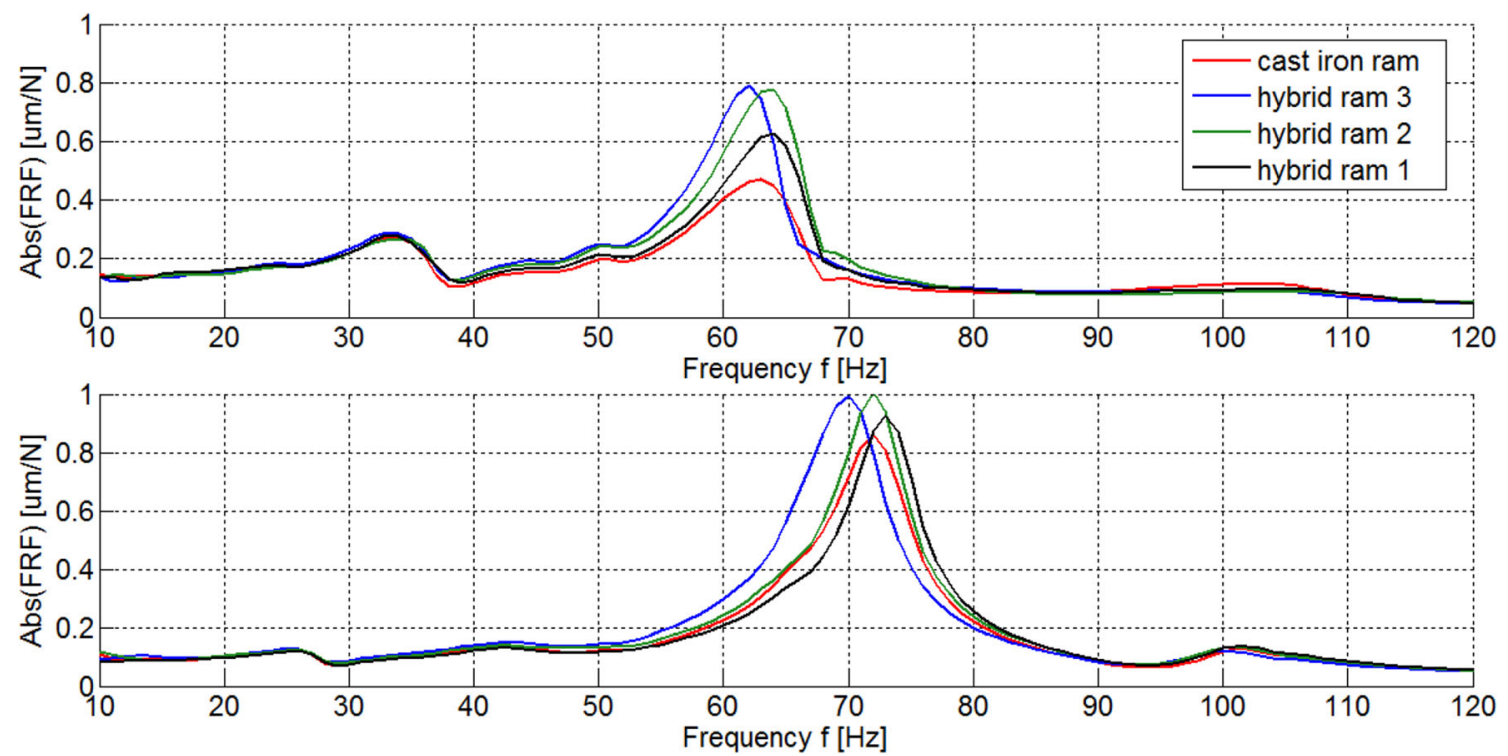

Fig. 14 Comparison of dynamic compliance in the horizontal direction (top) and in the vertical direction (bottom) of the assemblies with testing rams. See illustrative Eigenshapes on Fig. 15 and Fig. 16 


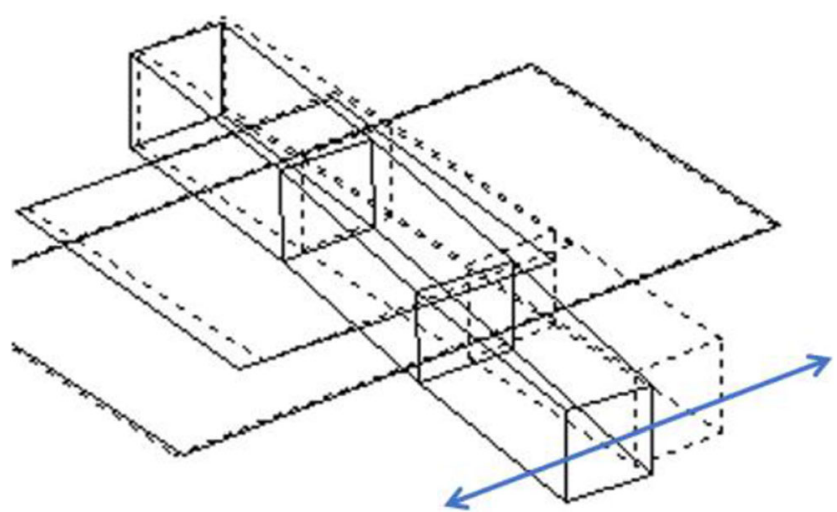

Fig. 15 Eigenshape of $63.5 \mathrm{~Hz}$ of the complete assembly with hybrid ram \#1

dimensions (see Fig. 9). The hybrid designs differed only in the composite reinforcement design:

- Hybrid \#1: Cast iron ram with fibre-epoxy composite reinforcement with the highest stiffness.

- Hybrid \#2: Cast iron ram with fibre-epoxy composite with 3 integrated layers of rubber bands for damping improvement.

- Hybrid \#3: Cast iron ram with fibre-epoxy composite with 4 integrated layers of rubber bands for damping improvement.

The rubber bands were integrated for potential further improvement of damping. On the other hand, the large compliance of the rubber material reduced the tube stiffness. The

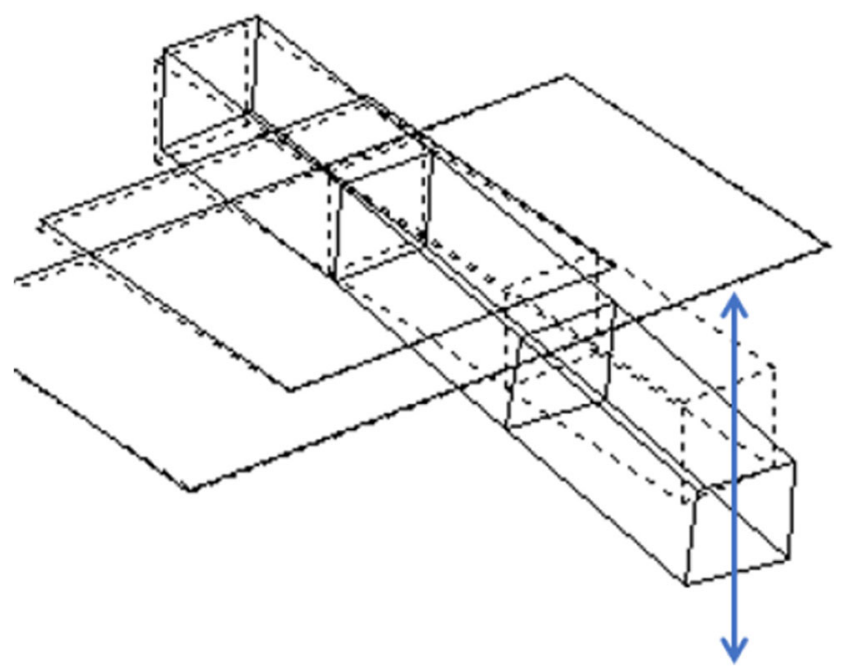

Fig. 16 Eigenshape of $73.2 \mathrm{~Hz}$ of the complete assembly with hybrid ram \#1 inner-outer diameters of the composite tubes were kept constant for all three versions.

An overview of ram properties is given in Table 4. The hybrid rams were approximately $40 \mathrm{~kg}$ lighter than the reference ram due to the reduced ductile cast iron wall thickness. The static stiffness parameters, which are given in Table 4, were obtained using finite element analysis for the ram in a testing assembly. Due to the reduced ductile cast iron wall thickness and different stiffness of the composite reinforcements, only the static stiffness of the hybrid \#1 version was better than the stiffness of the reference body. The static stiffness of the hybrid \#2 and hybrid \#3 designs was reduced. On the other hand, it was assumed that their dynamic stiffness would be compensated by damping improvement.

\subsubsection{Testing of the rams as stand-alone parts}

The first experimental modal analysis testing was performed in a configuration, where the spindle rams were placed on a flexible rope (see Fig. 10). This boundary condition configuration was used to minimize the influence on the damping evaluation. For the testing, a lumped mass of $33 \mathrm{~kg}$ simulating the mass of a spindle was mounted to the front wall of each ram. This additional lumped mass was attached in order to balance the ram load to the same value and compensate the mass differences between the reference and hybrid designs. The dynamic behaviour is compared in Fig. 11, where the frequency response functions of dynamic compliance absolute values are shown for all four designs.

The results summarized in Table 5 and Fig. 12 present the damping ratio improvement and the dynamic stiffness improvement of the hybrid design. The values in Table 5 are given for the first two mode shapes that occur when the system is excited in one direction. The average damping ratio was evaluated from 5 mode shapes. As can be observed, the hybrid design leads to damping that is at least two times higher than the reference metal body. The integration of damping layers resulted in an even larger improvement of the damping ratio. On the other hand, the obtained damping values of hybrid coupons are lower than the values obtained during the experiments with material structure coupons (see Sections 4.2 and 4.1). This is demonstrated when comparing the hybrid design application on closed profiles in Fig. 8 and Fig. 11. The hybrid thick-walled cast iron-composite spindle ram designs resulted in the average damping ratio $0.08-0.13 \%$, which were $2-3$ times higher values than the reference cast iron body results. The hybrid thin-walled steel-metal profile had the average damping ratio $0.16 \%$, which presented the improvement by a factor of 4 in comparison with the reference steel coupon. The first mode shapes of the thin-walled hybrid profile had even higher damping ratios as the values were close to 0.20 


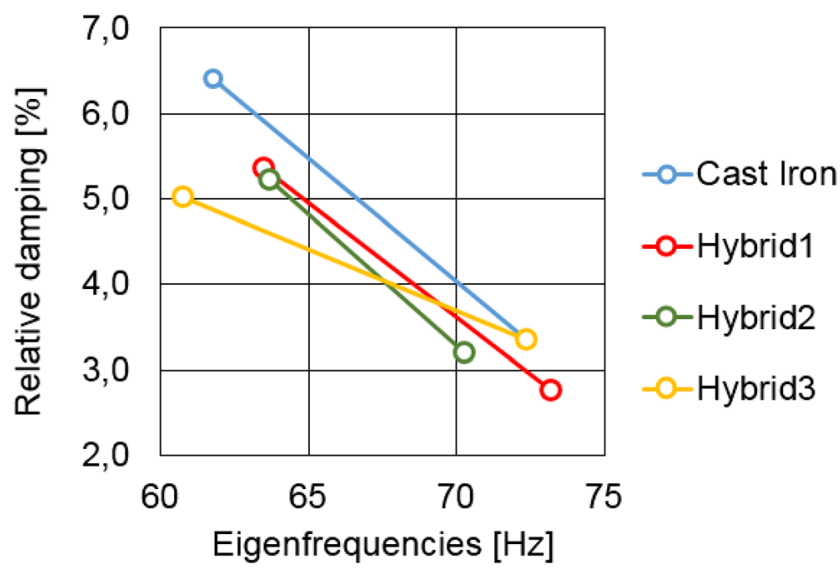

Fig. 17 Comparison of relative damping on the first and second frequency for various ram coupons in the test rig assembly

$0.25 \%$. While there is a difference in damping of the basic metals (steel, ductile cast iron); the main difference for the damping and dynamic compliance reduction was in the different design approach for the hybrid coupon and the hybrid spindle rams. For the thin-walled body, the hybrid coupon was created from the reference steel body by adding additional composite layer, which significantly improved static stiffness, which coupled with a damping improvement led to a major dynamic compliance reduction. The thick-walled hybrid coupons were designed to have similar static stiffness in bending as the reference ductile cast iron body. The ductile cast iron was placed on the outer part of the square like cross-section with the inner circular hole and the composite part was designed as an inner tube. Therefore, due to higher second moment of area of the metal part, the effect of metal on structural properties reduced the possible damping and dynamic stiff- ness improvement by the inner composite reinforcement. The design concept used for hybrid model rams is much closer to the real industrial application than the concept of outer composite reinforcement, which would for example make difficult to manufacture connection interfaces at the demanded precision and quality. Therefore, the 2-3 times increase in the average damping ratio for hybrid metal-composite designs should be more expected for those designs than the higher values from the basic coupons. Generally, the hybrid spindle rams vs the reference ductile cast iron ram can be evaluated that due to the higher damping and lower weight, the maximum absolute value of dynamic compliance was lower for all of the hybrid designs than for the reference body.

\subsubsection{Testing of rams in an assembly}

Another type of test was performed at a model test rig. The test rig consists of a bed and a ball-screw-driven movable table. The spindle rams were attached to the top side of the table using steel clamps, which were connected to the table and ram by bolts. Identically to the previous test, the lumped mass of $33 \mathrm{~kg}$ was attached to the front panel of the ram. The configuration is shown in Fig. 13. Finally, the assembly included several structural parts and also various typical connection interfaces: rolling linear guideways, a ball-screw drive and the mounting of the test rig to the ground. A dynamic behaviour comparison is shown in Fig. 14 and the evaluated properties are presented in Table 6.

The effect of damping in connection interfaces and other assembly inputs completely negated the improved damping behaviour of the rams observed during the stand-alone exper-
Table 7 Proportion of damping ratios: Hybrid material coupons vs. iron-based coupons

\begin{tabular}{llll}
\hline Coupon type & Material type: & Average damping (\%) & Ratio hybrid vs. iron-based \\
\hline Elementary coupons 2D & Steel coupon & 0.04 & \\
(Table 2) & C-composite coupon & 0.28 & 6.28 \\
& Hybrid coupon & 0.25 & \\
Large scale 3D coupon & Steel coupon & 0.04 & \\
(Table 3) & C-composite coupon & 0.33 & 4.00 \\
& Hybrid coupon & 0.16 & \\
Ram stand-alone & Cast iron ram & 0.04 & 2.00 \\
(Table 5) & Hybrid coupon \#1 & 0.08 & 3.00 \\
& Hybrid coupon \#2 & 0.12 & 3.25 \\
& Hybrid coupon \#3 & 0.13 & \\
Ram in assemly & Cast iron ram & 4.88 & 0.84 \\
(Table 6) & Hybrid coupon \#1 & 4.10 & 0.86 \\
& Hybrid coupon \#2 & 4.20 & 0.86 \\
\hline
\end{tabular}


Fig. 18 Proportion of damping ratios (solid colour bars, hybrid material coupons vs. iron-based coupons) and dynamic compliance on critical

Eigenfrequency (hatched colour bars, iron-based coupons vs. hybrid material coupons). Higher values mean better relative results

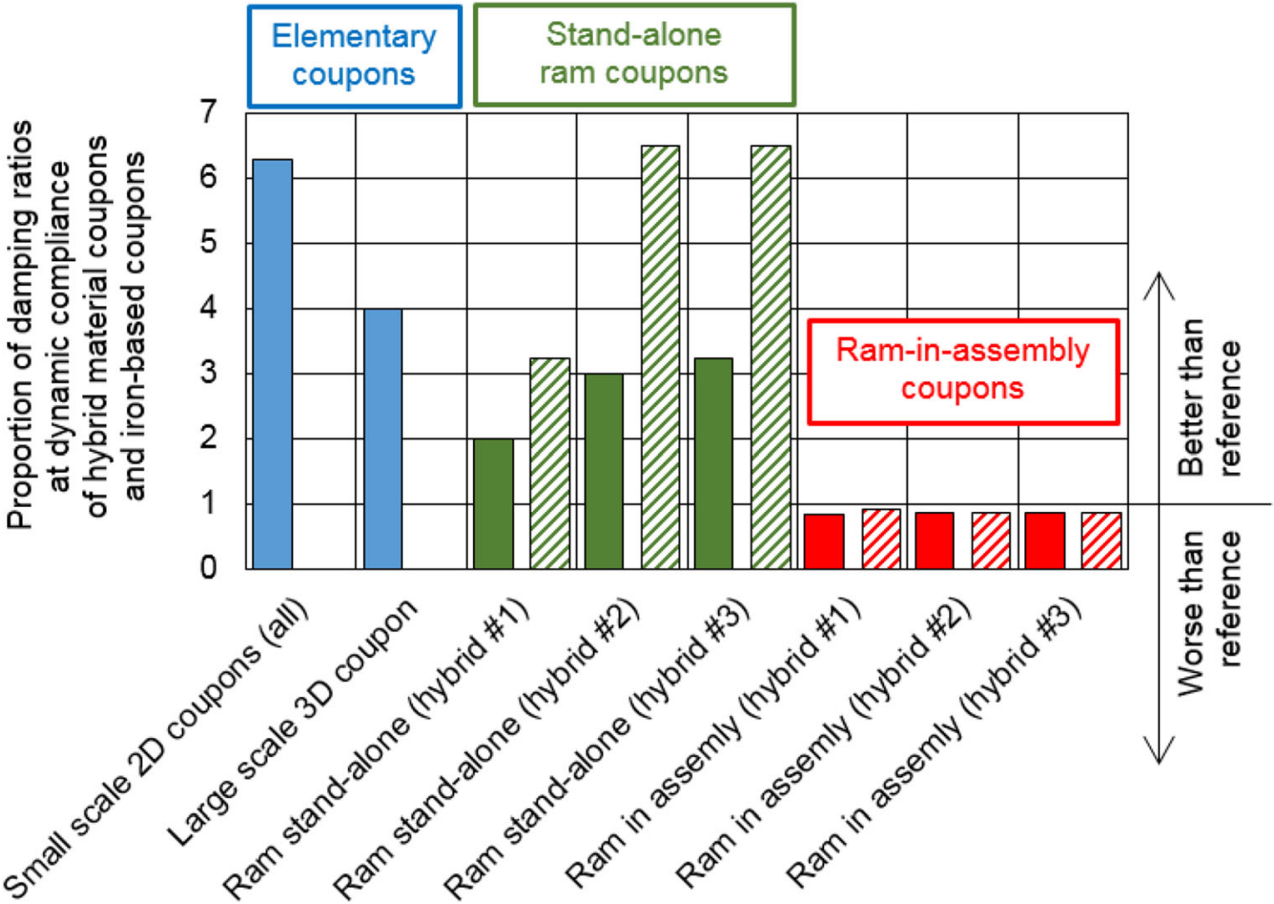

iments. All three hybrid rams achieved higher dynamic compliance and lower damping on the most dominant mode shapes. The only comparable behaviour was shown by the hybrid \#1 design, which had the largest static stiffness of the hybrid parts. The integration of damping layers did not result in any detectable damping improvement of the assembly configuration (Fig. 17).

\subsection{Fibre composite coupons summary}

In this section, a summary of the experimental results from the previous subsections is provided. An overview of values is shown in Table 7 . The results are also visually summarized in Fig. 18.

When the elementary hybrid coupons from the fibre composites-steel combination were tested, the average damping ratio was in the range of $0.16-0.32 \%$, which was approximately 4 to 8 times higher than for the steel design. The damping values of the fibre composite and hybrid coupons depended on the fibre type, orientation,

Table 8 Damping ratio of particle composites

\begin{tabular}{lll}
\hline Coupon & Damping ratio (\%) & Standard deviation (\%) \\
\hline REC & 4.79 & 1.88 \\
GREC & 1.88 & 0.09 \\
\hline
\end{tabular}

layer thickness and other parameters. The density of the fibre composites is approximately 4 times lower than of the steel materials. Since the fibre composites can provide structural stiffness reinforcement, the total weight increase is not significant.

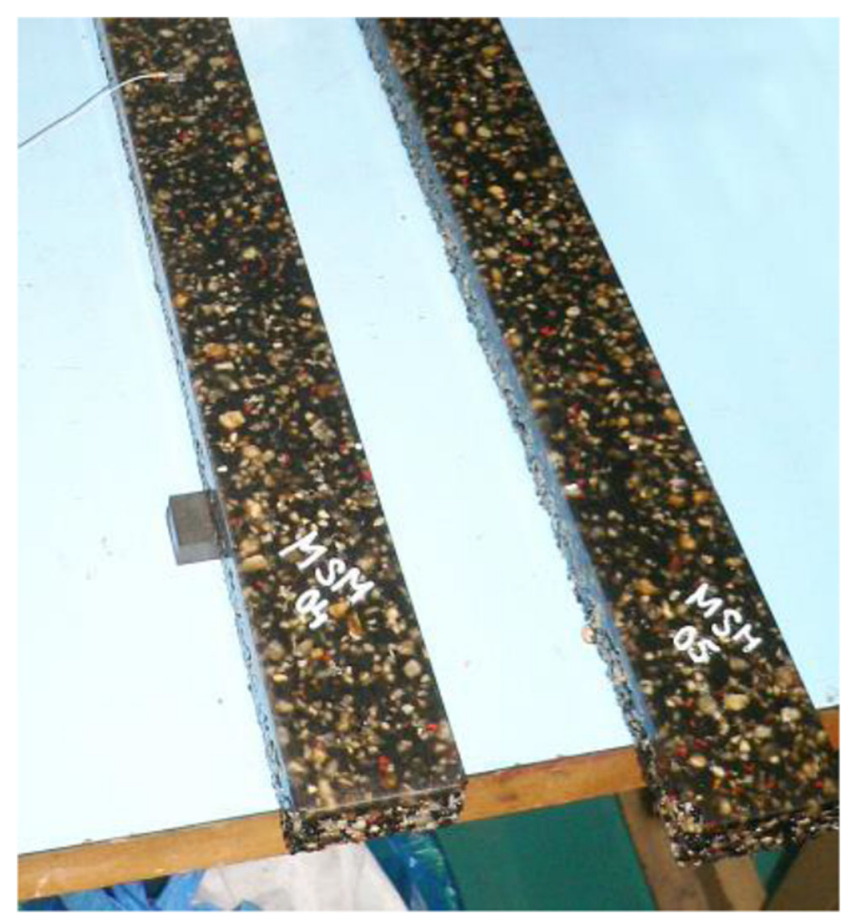

Fig. 19 Beam coupons made from particle composites 


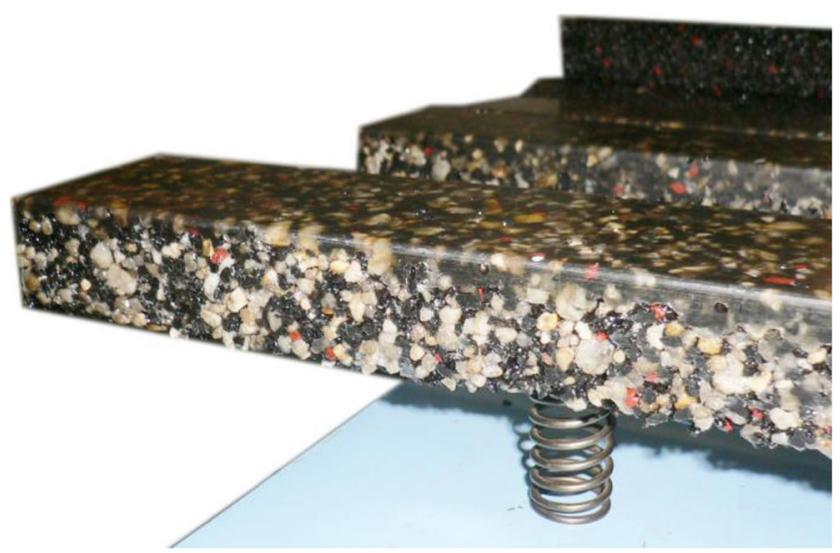

Fig. 20 Boundary conditions - beams on flexible springs

In the stand-alone configuration testing, the application of the hybrid metal-fibre composites into the machine tool structural part (ram) led to a damping ratio that was 2-3 times higher than the reference ductile cast iron. The presence of the rubber layers in the composite reinforcement resulted in additional damping improvement in comparison with the fibre composite-only reinforcement. Although implementation of the rubber layers causes lower static stiffness of the coupons, the final dynamic compliance improved due to the higher damping ratio and lower mass.

The mass reduction of all hybrid rams was about $27 \%$ compared to the cast iron ram, due to the wall reduction. The increased damping and lower mass of the ram bodies did not, however, improve the total dynamic behaviour of the tested ram in the assembly. The highest assembly damping and the lowest dynamic compliance were evaluated for the version with the reference ductile cast iron ram with the lowest body damping, as the effect of damping of the connection interface and other assembly parts prevailed. The second best dynamic compliance results were achieved by the hybrid structure with the composite reinforcement, whose static stiffness was not reduced by the presence of compliant rubber layers. The assembly consists of more heavy parts. Therefore, damping of the composite and composite rubber tubes in the ram could not affect the final results due to the relative low energy potential.

\section{Damping potential of hybrid structures based on particle composites}

In this section, the damping properties of the hybrid structures based on particle fillers and steel base materials are experimentally analyzed. The effect of the added particle fillers was evaluated in several steps. Firstly, the elementary behaviour of the particle filler coupons was tested (see Section 5.1). Secondly, the behaviour of the elementary hybrid structure properties consisting of a steel profile with various particle fillings is presented (see Section 5.2). The last step focused on the structural part. Examples of a five-axis milling centre spindle ram and horizontal lathe spindle stock with particle fillings were tested in a stand-alone configuration and in an assembly configuration (see Sections 5.3 and 5.4). The damping ratio changes observed in all of the experimental data
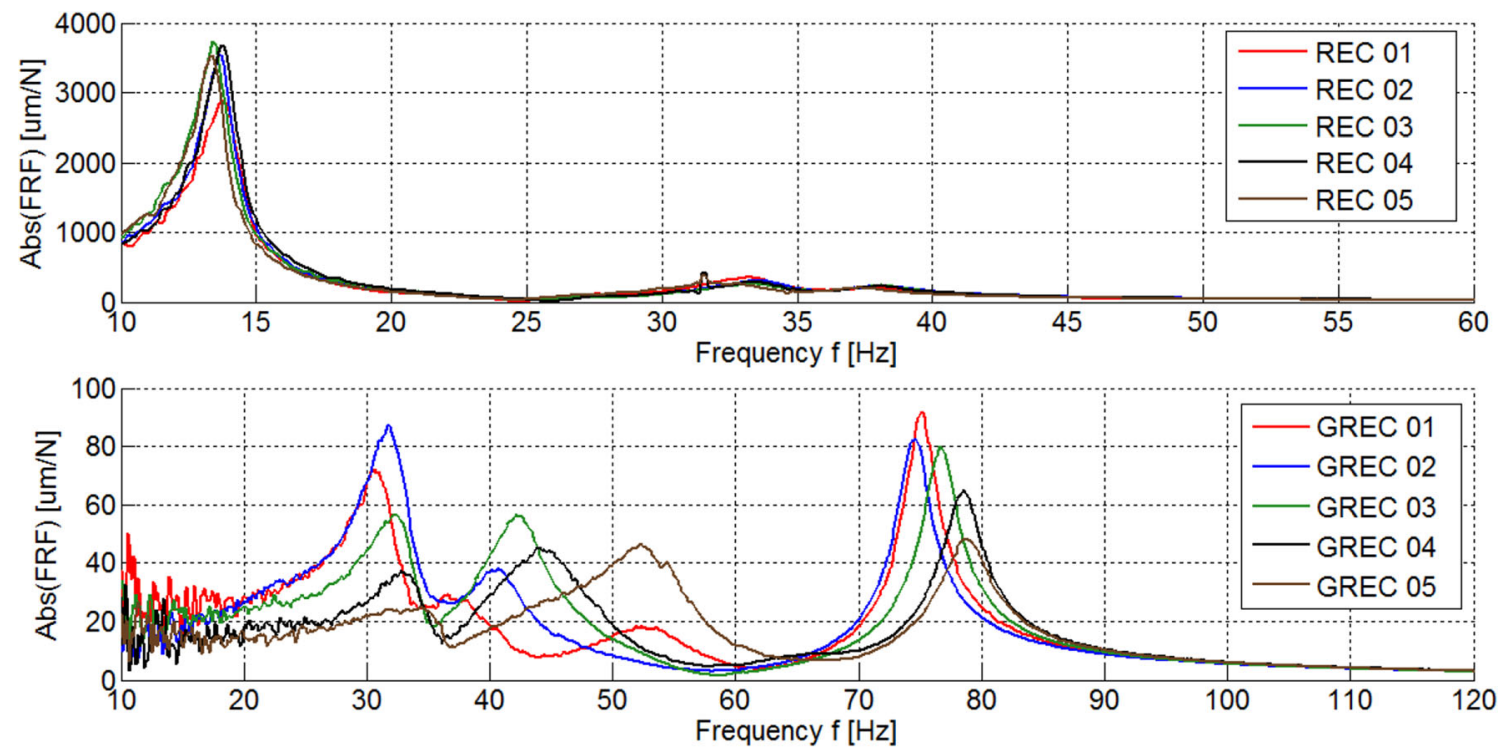

Fig. 21 Dynamic compliance frequency transfer functions of the REC coupons (top) and the GREC coupons (bottom). An extreme dynamic compliancy of the rubber compound compared to the rubber-grit compound is visible 
Table 9 Comparison of modal properties for profile coupons with particle composites (the five most important structural frequencies within the range of $100-1.000 \mathrm{~Hz}$ are taken into account)

\begin{tabular}{|c|c|c|c|c|c|c|}
\hline \multirow[t]{2}{*}{ Mode } & \multicolumn{2}{|l|}{ Steel } & \multicolumn{2}{|c|}{ Steel+GREC } & \multicolumn{2}{|c|}{ Steel+REC } \\
\hline & $f(\mathrm{~Hz})$ & $\zeta(\%)$ & $f(\mathrm{~Hz})$ & $\zeta(\%)$ & $f(\mathrm{~Hz})$ & $\zeta(\%)$ \\
\hline 1 & 137 & 0.01 & 214 & 0.12 & 179 & 1.61 \\
\hline 2 & 179 & 0.07 & 466 & 0.15 & 234 & 4.21 \\
\hline 3 & 193 & 0.01 & 502 & 0.19 & 313 & 3.08 \\
\hline 4 & 281 & 0.01 & 528 & 0.44 & 381 & 3.98 \\
\hline 5 & 339 & 0.01 & 897 & 0.46 & 458 & 2.33 \\
\hline Average damping ratio & & 0.02 & & 0.31 & & 2.73 \\
\hline 1st bending mode shape damping & & 0.01 & & 0.12 & & 1.61 \\
\hline
\end{tabular}

are discussed in Section 5.5. Material parameters of the filling particle composite are described in Section 3.2.

\subsection{Damping of particle composite filler}

As mentioned in Section 3.2, the particle composite fillers consist of particles (stone, rubber) and epoxy resin. The mixture can be poured into the machine part structures before the epoxy resin cures. The basic experiments for material damping value estimation were performed on beams made from the particle composite filler itself. Coupons (see Fig. 19) of cross-section $70 \times 40 \mathrm{~mm}$ and length $700 \mathrm{~mm}$ were produced using a mould. Five coupons were prepared for both the mixtures, i.e. REC (rubber epoxy compound) and GREC (grit rubber epoxy compound). Due to the flexibility of the coupons, especially the coupons made of rubber-epoxy compound, it was necessary to use boundary conditions where the beams are placed on springs between the beam and the base (see Fig. 20). The response of the coupons to modal excitation is shown in Fig. 21. The results demonstrated that the REC coupons had very good property repeatability. On the other hand, the GREC coupons were made with a wide property variation, which was caused by a variation of the internal structure made from rubber particles, grit of different sizes and epoxy resin. The average damping ratios of the coupons are shown in Table 8 .

\subsection{Damping of elementary hybrid coupons}

The purpose of the analysis was to study the coupons' damping increase behaviour on large-scale dimensions, which were closer to the real structural parts' dimensions than the previous material coupons. The hybrid large scale coupons were composed of a steel profile that was filled with the particle composite (see Fig. 22). The coupons were designed with a length of $1500 \mathrm{~mm}$. The steel profile cross-section was $100 \mathrm{~mm}$ by $300 \mathrm{~mm}$ and the wall thickness was $4 \mathrm{~mm}$. For the analysis, the hybrid filled coupons were placed on springs (see Fig. 23). The dynamic response of the coupons to the excitation refers to the reference steel coupon, and the hybrid coupons filled with the REC and GREC mixtures are shown in Fig. 24. The structural Eigenshapes of the hollow (nonfilled) profile were identified from measured results with support of the simple FE model. The other peaks measured on the hollow steel profile are related to so-called substructural shapes (local vibration of the wall) which are not relevant for the comparison. The modal parameters of the five most important structural Eigenfrequencies are given in Table 9.

The hybrid steel-particle composite structure demonstrated options for improving the steel structure dynamic
Fig. 22 Cross-section of hybrid steel-particle composite profile
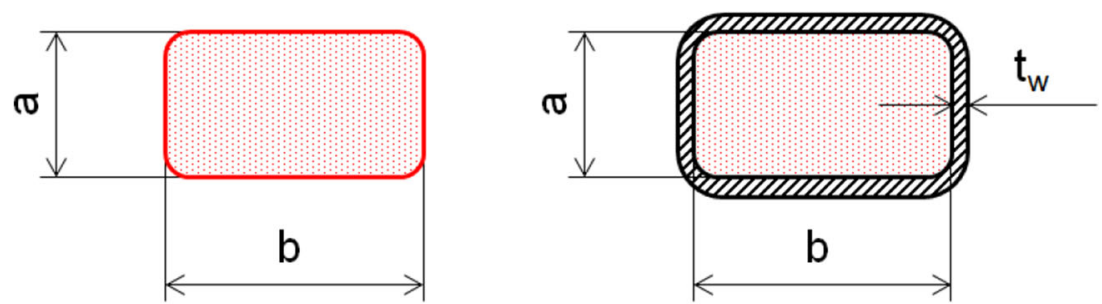

mammm thin-walled steel profile particle composite filling 


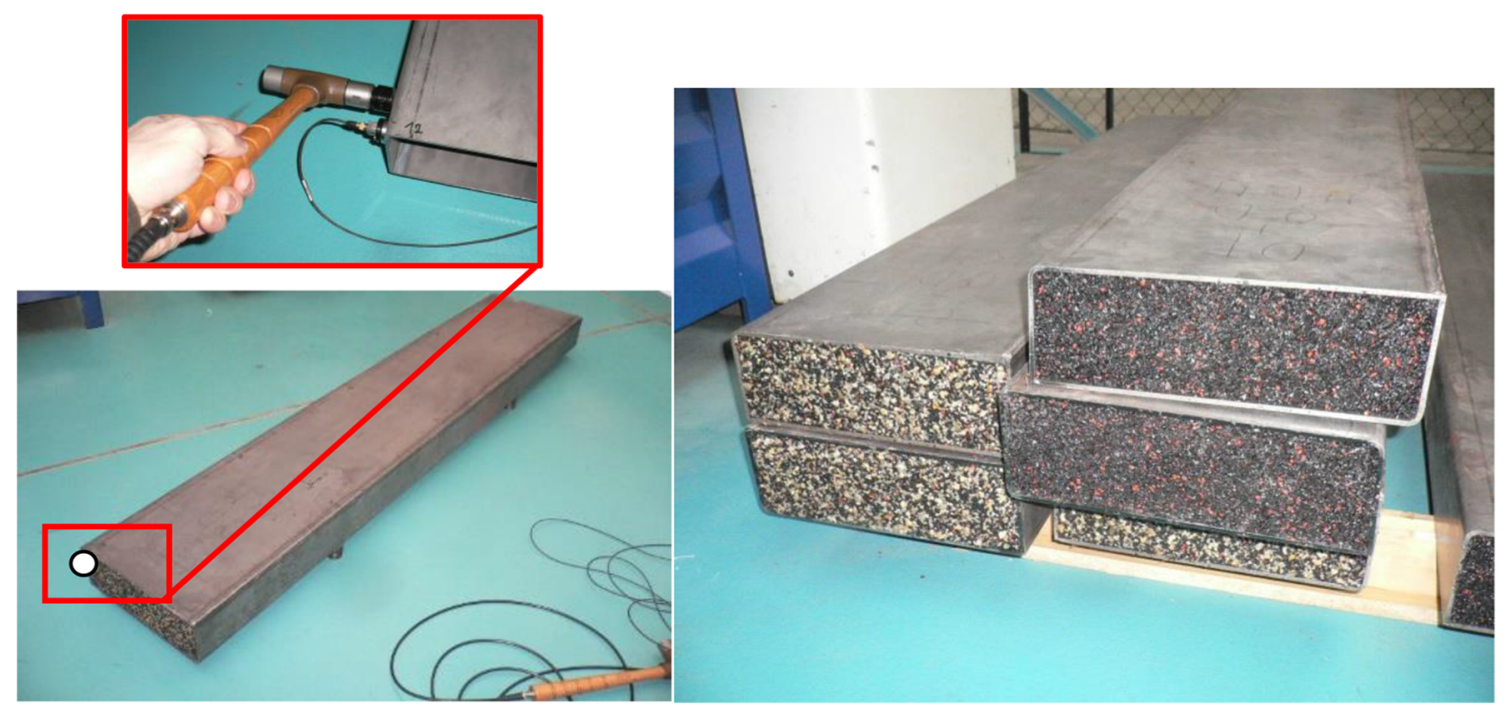

Fig. 23 Hybrid steel-particle composite profile coupon

$1^{\text {st }}$ structural Eigenshape:
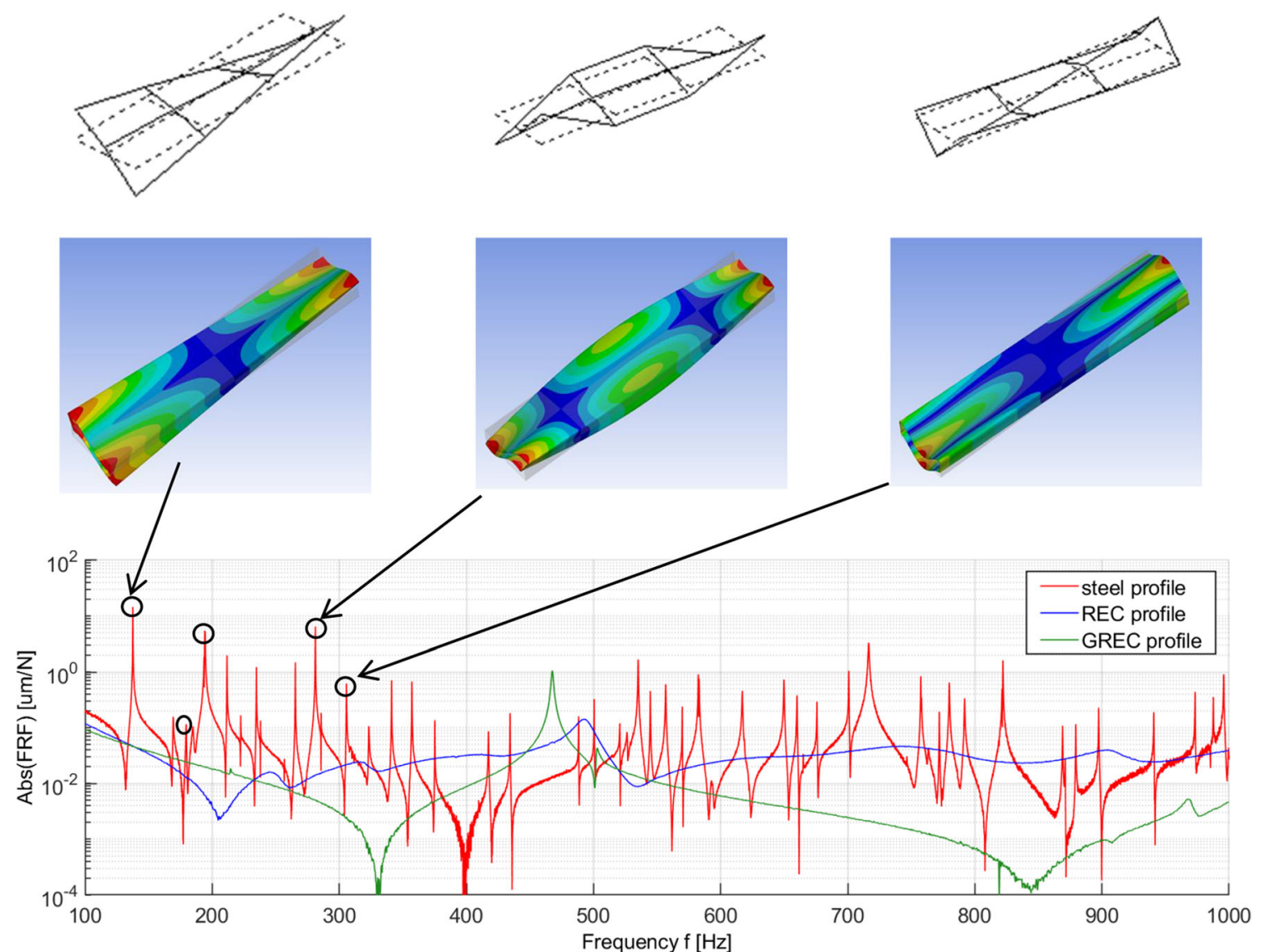

Fig. 24 Dynamic compliance (FRF) shows a comparison of various profile types. Many peaks due to substructural wall vibrations are visible on the steel coupon. The structural Eigenshapes are marked. The Eigenshapes obtained from the FE simulation should help to visualize the measured Eigenshapes on the selected structural Eigenshapes. These substructural vibrations can be damped with the profile filling - see the REC and GREC coupons. 
Fig. 25 Welded frame of original ram

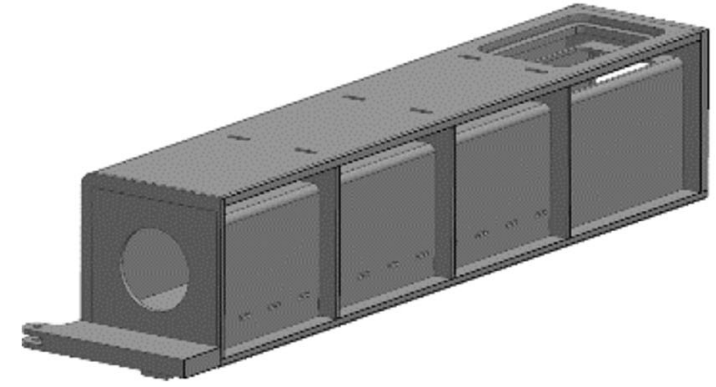

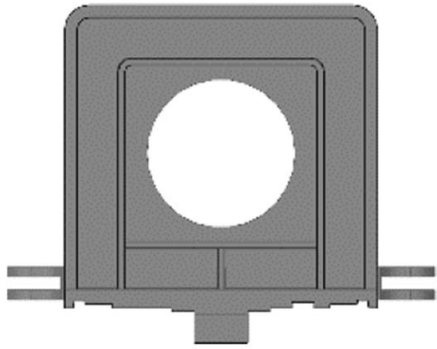

behaviour. For the GREC mixture, the average damping ratio was $0.31 \%$, which was higher by one order in comparison with the reference steel non-filled specimen. The ratio was similar to the damping ratios of hybrid fibre composite-steel components. The damping increased and the frequencies also significantly increased. However, the total structure mass rose to $61 \mathrm{~kg}$ from the original $37 \mathrm{~kg}$.

For the REC mixture using rubber-epoxy materials, the average damping ratio went up to $3 \%$, which was a promising result. On the other hand, the mass increase of 28 $\mathrm{kg}$, which was caused by adding a material with almost no stiffness, meant that the frequencies decreased in comparison with the reference body with the exception of the first frequency.

\subsection{Hybrid steel-particle composite spindle ram}

For the structural parts-spindle ram case, the ram of a five-axis high-speed machining milling centre was used. The ram is an example of a long slender structural part. The original ram, with cross-sectional dimensions of $380 \mathrm{~mm}$ by $368 \mathrm{~mm}$ and a length of $1820 \mathrm{~mm}$, is shown in Fig. 25. The ram connection interfaces were made using a pair of linear guideways and a gear rack, all placed on the bottom surface of the ram.

Three new rams were designed and compared with the original welded steel ram: the modified welded ram, the ram with the REC mixture and the ram with the GREC mixture. The redesign focused on making it possible to fill the cavities between the ram's inner and outer steel plates with the composite filler. The external dimensions and connection interfaces of the reference design were preserved for the new designs. The redesign was driven by the need to remove the transversal ribs of the original ram, which limited the volume of cavities to be filled and also by the need to reduce the mass of the welded frame. Therefore, the ram for the hybrid design was converted using only the transversal ribs and using a more symmetrical internal design, as can be seen in Fig. 26, in which the space for fillers is also highlighted. The goal of the numerical optimization was to achieve a static stiffness of the ram damping matching the original ram properties. The 52-kg mass reduction in the modified welded frame was designed through a finite element analysis of the ram.

All four rams were manufactured and tested. Their static stiffness and mass properties are compared in Table 10. The static stiffness values, which were obtained using finite element analysis, are valid for the configuration of the simplified assembly, which is the second type of test described in the study.

- Original steel ram: welded steel ram with the original rib structure

- Modified steel ram with no filling: modified welded ram with different ribs and structural sheet design enabling pouring of the filler

- Modified steel ram with REC filling: hybrid ram using the modified welded steel ram filled with rubber epoxy compound between the outer and inner structural sheets
Fig. 26 Modified hybrid ram frame filled with fillers
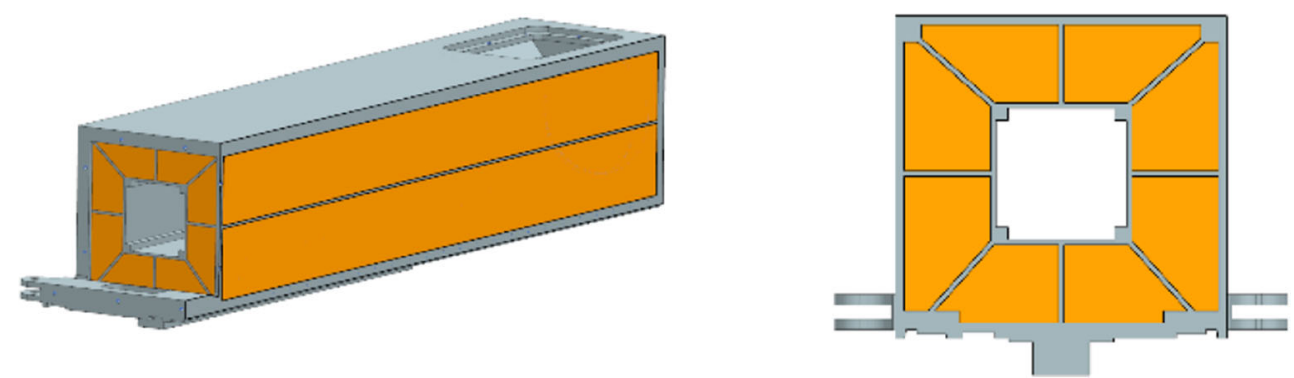
Table 10 Comparison of hybrid ram designs

\begin{tabular}{|c|c|c|c|c|}
\hline & \multicolumn{2}{|c|}{$\begin{array}{l}\text { Static stiffness horizontal/ } \\
\text { vertical }\end{array}$} & \multirow{2}{*}{$\begin{array}{l}\text { Total } \\
\text { weight } \\
(\mathrm{kg})\end{array}$} & \multirow{2}{*}{$\begin{array}{l}\text { Thereof filler } \\
\text { weight } \\
(\mathrm{kg})\end{array}$} \\
\hline & $\begin{array}{l}\text { k_hor } \\
(\mathrm{N} / \mathrm{um})\end{array}$ & $\begin{array}{l}\text { k_ver } \\
(\mathrm{N} / \mathrm{um})\end{array}$ & & \\
\hline Original steel ram & 35.0 & 27.5 & 478 & \\
\hline Modified steel ram with no filling & 34.0 & 34.5 & 426 & \\
\hline Modified steel ram with REC filling & 34.8 & 35.7 & 513 & 87 \\
\hline Modified steel ram with GREC filling & 37.2 & 38.8 & 608 & 182 \\
\hline
\end{tabular}

- Modified steel ram with GREC filling: hybrid ram using the modified welded steel ram filled with grit rubber between the outer and inner structural sheets

The rams were tested in two configurations to compare their modal properties. In the first configuration, the rams were tested in a stand-alone configuration, while in the second configuration, the rams were tested using a simplified assembly with connection interfaces.

\subsubsection{Testing of the rams as stand-alone parts}

In this measurement, the rams were placed on a compliant fixture for the modal analysis (see Fig. 27). A lumped mass of $33 \mathrm{~kg}$ made of a steel block was connected to the front of the ram to simulate the mass of the milling head. The frequency response function of dynamic compliance absolute values is shown in Fig. 28. The average damping calculated from the first eight modes and the damping of the first most compliant bending mode shape are shown in Table 11.

The average damping of the welded ram was around $0.09 \%$ for the original ram. Due to the structural redesign, an average damping ratio of $0.24 \%$ for achieved using welded steel only. The average damping ratio increased from 0.24 to $0.92 \%$ when using the REC mixture and to $0.45 \%$ when using the GREC mixture. When comparing the values at the first bending mode shape, the steel frames had a damping ration of
$0.05 \%$ for the reference body, $0.14 \%$ for the steel non-filled body, $0.25 \%$ for the REC ram and $0.16 \%$ for the GREC ram. From the ram stand-alone evaluation, the particle composite application seems very optimistic in terms of dynamic behaviour improvement. Due to the added mass of the fillers, the first bending frequency decreased from $472 \mathrm{~Hz}$ for the steel ram to $439 \mathrm{~Hz}$ for the REC ram and $435 \mathrm{~Hz}$ for the GREC ram.

\subsubsection{Testing the rams in an assembly}

The following measurements were performed in a simplified assembly. The rams were connected to the base plate using a pair of linear guideways with four housings and a simplified axial fixture instead of a ball screw drive. A lumped mass of $33 \mathrm{~kg}$ supplying the milling head was used again. The idea was to test all the rams in equal conditions to see how the improved ram damping is transferred in the assembly with major damping sources in the linear guideway housings. For the test, a simple clamping plate with the connections for housings and other fixtures was designed and clamped to the measuring base. The configuration of experiments is shown in Fig. 29.

A comparison of dynamic compliances is shown in Fig. 30 for the excitation in the vertical and horizontal direction. The evaluated properties are given in Table 12.

The first mode shape corresponded to the first bending mode in the horizontal direction, while the second mode shape corresponded for the first bending mode in the vertical
Table 11 Comparison of average damping and damping of the most compliant mode shape for standalone spindle rams

\begin{tabular}{lllll}
\hline & Damping & \multicolumn{2}{l}{ First bending mode } & \multirow{2}{*}{ Compliance } \\
& $\zeta_{\text {avg }}(\%)$ & $f_{\text {bending }}(\mathrm{Hz})$ & $\zeta_{\text {bending }}(\%)$ & \\
\hline Original steel ram & 0.09 & 489 & 0.05 & 0.71 \\
Modified steel ram with no filling & 0.24 & 474 & 0.14 & 0.39 \\
Modified steel ram with REC filling & 0.92 & 443 & 0.25 & 0.22 \\
Modified steel ram with GREC filling & 0.45 & 446 & 0.16 & 0.26 \\
\hline
\end{tabular}


Fig. 27 Experimental modal analysis of stand-alone steel or hybrid spindle rams

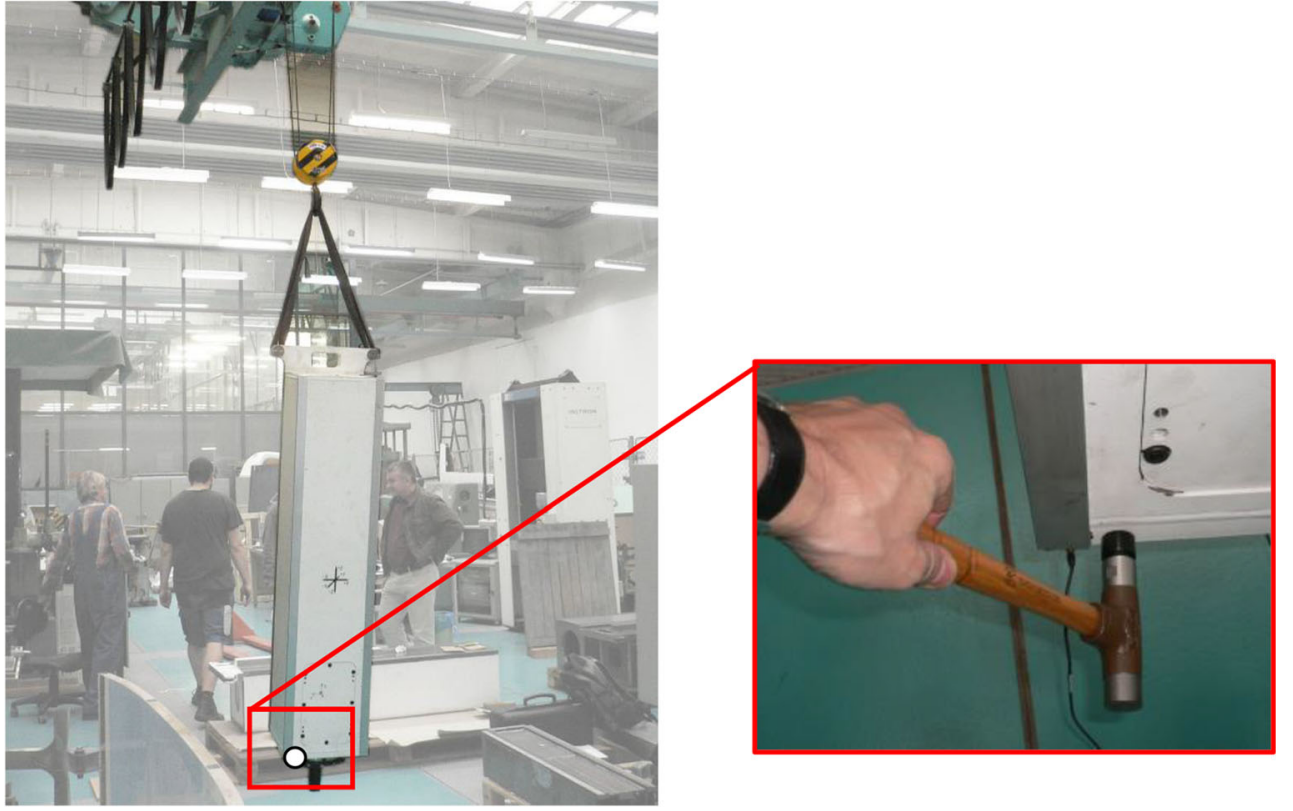

direction. Average damping ratios were obtained from the first eight modes.

As the damping in the connection interfaces is responsible for the major part of the damping in the assembly, the increase by the hybrid structure was significantly smaller than in the previous tests. The average damping ratio increased from $0.83 \%$ for the original steel to $1.24 \%$ only through application of a different steel design with a different internal structure and vibration behaviour. The highest damping was achieved by a particle composite filler based on the GREC mixture, which combines stiffness and damping improvement at the cost of higher added weight. The improved stiffness and damping resulted in higher dynamic stiffness and the potential for improved machine tool productivity. On the other hand, when the GREC mixture was used, the mass was raised by $27 \%$ in comparison with the original steel design. The REC mixture hybrid spindle ram had large vibration damping for the stand-alone system. In the assembly, the average damping was similar to the modified steel design and the body damping improvement did not result in damping modification of the assembly. Due to the lower static stiffness, dynamic stiffness did not improve.

\subsection{Hybrid steel-particle composite spindle stock}

The particle filler's influence on structure damping was also tested on a lathe spindle stock. The lathe spindle stock is an example of a compact bulk structural part. The original spindle stock was made of cast iron with outer dimensions of $445 \times 445 \times 450 \mathrm{~mm}$ and a total mass of $183 \mathrm{~kg}$. In the original machine tool assembly, the spindle stock was connected to the machine bed using bolted joints. A beltdriven spindle was mounted inside the spindle stock. The basic idea was to convert the cast iron body into the hybrid body using the GREC mixture filling in the inner spindle stock cavities. The modal property changes were then

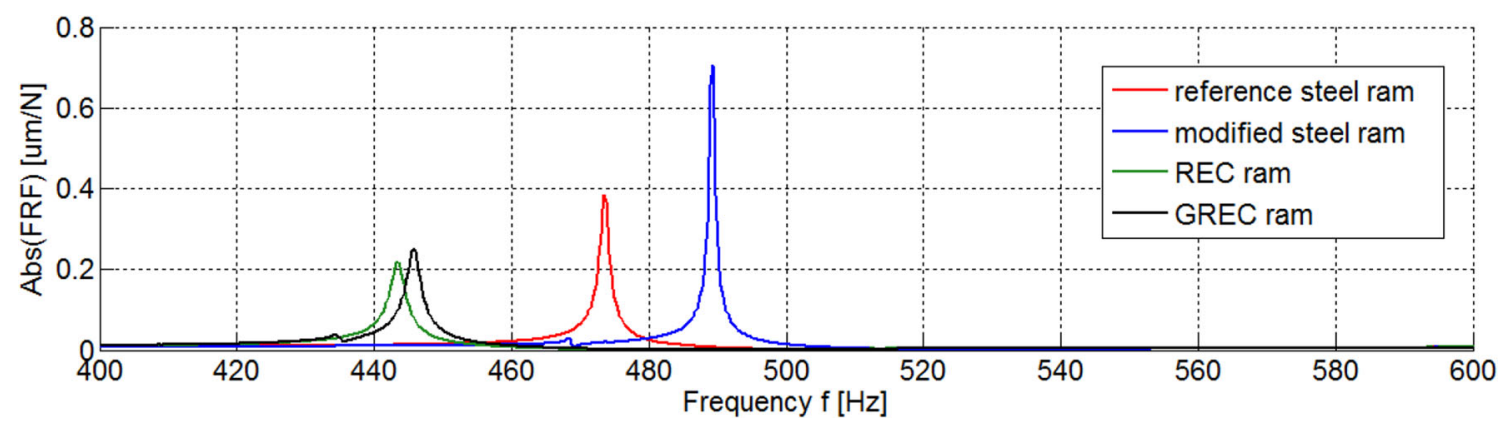

Fig. 28 Comparison of dynamic compliance of the stand-alone rams 
Fig. 29 Configuration for ram measurement in a simplified assembly
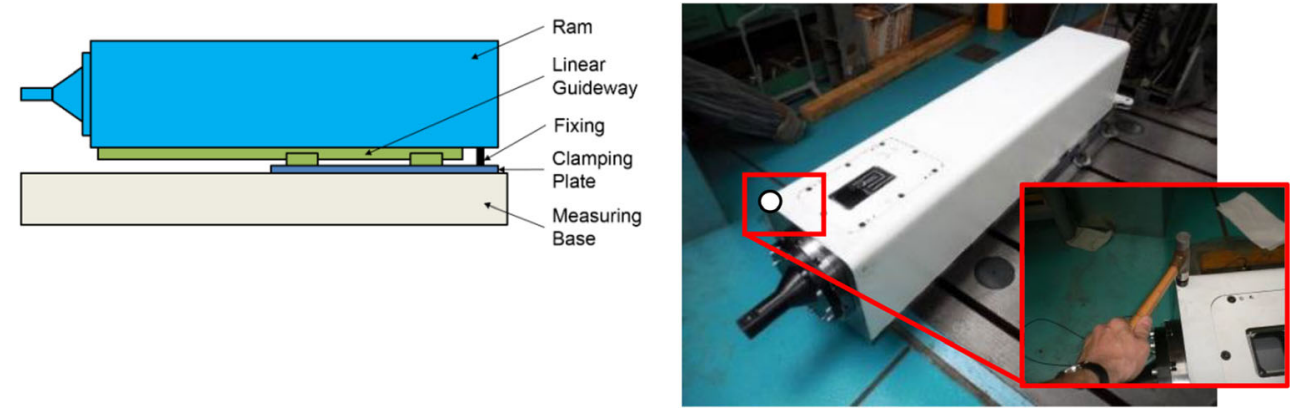

evaluated on the spindle stock body itself and also on the lathe assembly.

The modifications of the spindle stock into the hybrid stock were minor. A tube cover was placed into the stock to maintain a space for the spindle free of particle composites. A second modification was necessary due to the technology of the filling: a hole was machined into the stock, which enabled the cavity to be filled. The hole was later covered using a metal plate with bolted joints. A model of the hybrid stock is shown in Fig. 31. The mass of the hybrid spindle stock increased from 183 to $250 \mathrm{~kg}$, as $67 \mathrm{~kg}$ of the GREC mixture was used to fill the cavity.

\subsubsection{Testing of spindle stocks as stand-alone parts}

The modal properties of the spindle stock bodies were measured on a compliant fixture (see Fig. 32). A comparison of the results is given in Fig. 33. The average damping ratio was derived from the first six identified modes; the values are given in Table 13.

The effect of the conversion from the cast iron structure into the hybrid structure led to a change of the average damping ratio from 0.15 to $1.11 \%$, i.e. the damping increased almost ten-fold. The amplitudes of dynamic compliance were significantly reduced for the hybrid body.

\subsubsection{Testing of the spindle stocks in an assembly}

The following comparison was made in a full lathe assembly, where the reference cast iron or the hybrid spindle stock was mounted. The excitation and response measurement were performed on the chuck mounted to the spindle placed in the spindle stock (see Fig. 34). An evaluation of the modal properties at the lathe chuck is given in Table 14. The dynamic compliance behaviour is compared in Fig. 35.

The added mass of the filler had a negligible effect on the frequency of the mode shape with a maximum dynamic compliance. The damping ratio increased from 2.09 to $2.24 \%$ on the mode shape. Using the results from the previous measurement in a stand-alone configuration, 10-times higher stock damping resulted in only a $7 \%$ change of damping in the assembly. Due to the stiffness and small damping increase, the magnitude of dynamic compliance decreased from 0.13 to $0.11 \mu \mathrm{m} / \mathrm{N}$, which was a negligible reduction.

\subsection{Section summary}

The resultant damping ratios of the case studies are summarized in Table 15. The damping ratio and dynamic compliance results are visually presented in Fig. 36 and Fig. 37.
Table 12 Comparison of hybrid spindle rams in a simplified assembly

\begin{tabular}{|c|c|c|c|c|c|}
\hline & \multirow{2}{*}{$\begin{array}{l}\text { Damping } \\
\zeta_{\text {avg }}(\%)\end{array}$} & \multicolumn{2}{|l|}{ Excitation in $\mathrm{X}$} & \multicolumn{2}{|l|}{ Excitation in $\mathrm{Y}$} \\
\hline & & $\begin{array}{l}\zeta_{\text {bending vertical }} \\
(\%)\end{array}$ & $\begin{array}{l}|\mathrm{H}| \max \\
(\mathrm{um} / \mathrm{N})\end{array}$ & $\begin{array}{l}\zeta \text { bending horizontal } \\
(\%)\end{array}$ & $\begin{array}{l}|\mathrm{H}| \max \\
(\mathrm{um} / \mathrm{N})\end{array}$ \\
\hline Original steel ram & 0.83 & 0.76 & 1.20 & 1.56 & 2.80 \\
\hline $\begin{array}{l}\text { Modified steel ram with no } \\
\text { filling }\end{array}$ & 1.24 & 0.72 & 1.10 & 1.64 & 2.40 \\
\hline $\begin{array}{l}\text { Modified steel ram with REC } \\
\text { filling }\end{array}$ & 1.25 & 0.92 & 1.2 & 1.49 & 2.45 \\
\hline $\begin{array}{l}\text { Modified steel ram with } \\
\text { GREC filling }\end{array}$ & 1.51 & 1.35 & 0.92 & 1.58 & 1.48 \\
\hline
\end{tabular}



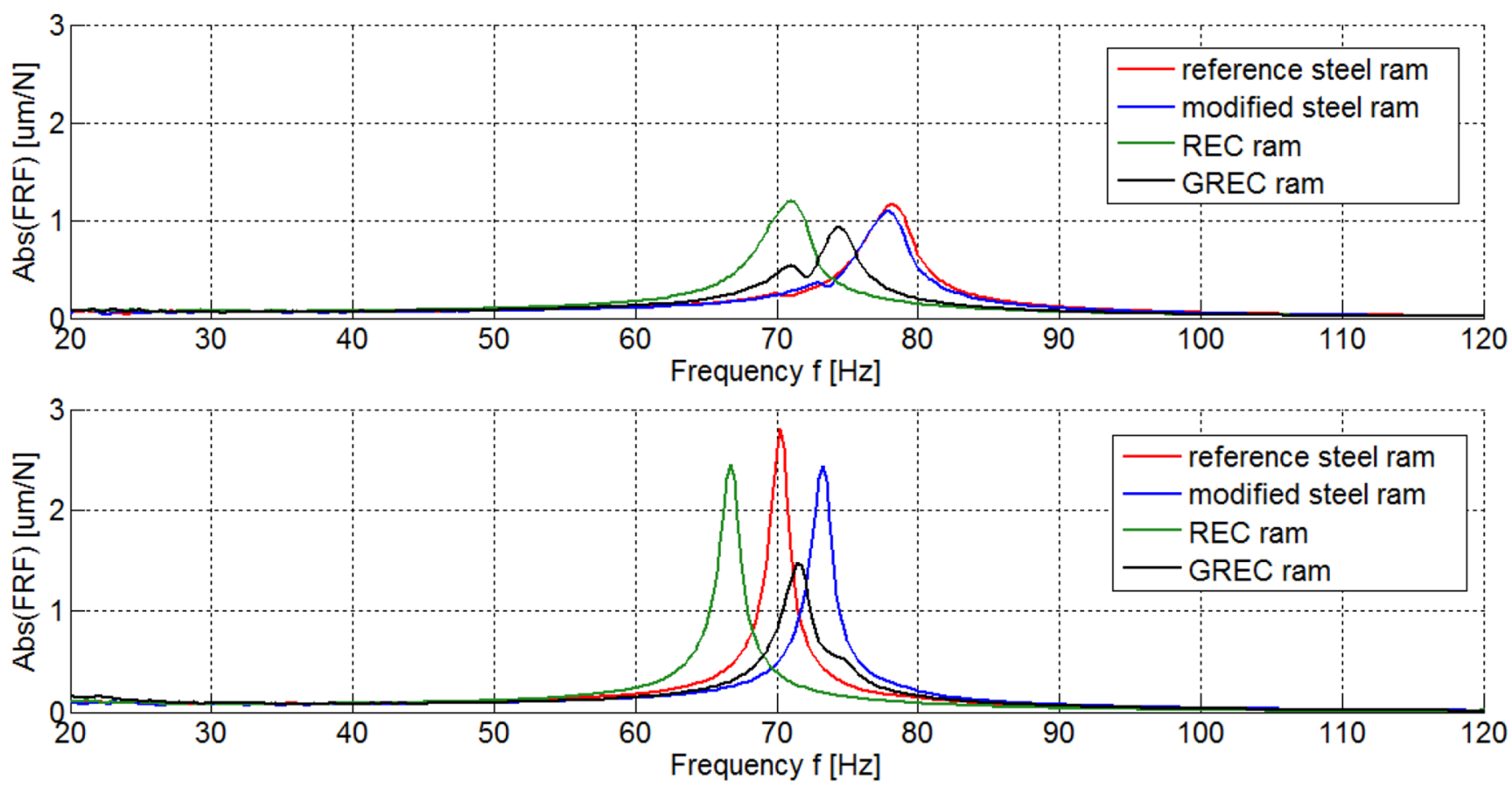

Fig. 30 Comparison of dynamic compliance of the ram assembly: excitation in the vertical direction (top) and in the horizontal direction (bottom)

The damping ratio of the particle composites depended on the particle mixture (grit, grit + milled rubber, resin content). In the tested application, the REC mixture with the high damping properties achieved damping values that were two orders higher than steel, not only for the basic material coupon but also for the hybrid steel profile - the particle composite coupon. On the other hand, this mixture has very low stiffness and the hybrid structure had problems with suppression of wall vibrations. The GREC mixture, which is made as a stiffer and less damped composite, increased the damping value only by one order in comparison with steel when the basic hybrid coupon was evaluated. The mixture stiffness is sufficiently high and the hybrid structure can suppress the hybrid skin vibration. The issue with the mixture is density, as the value
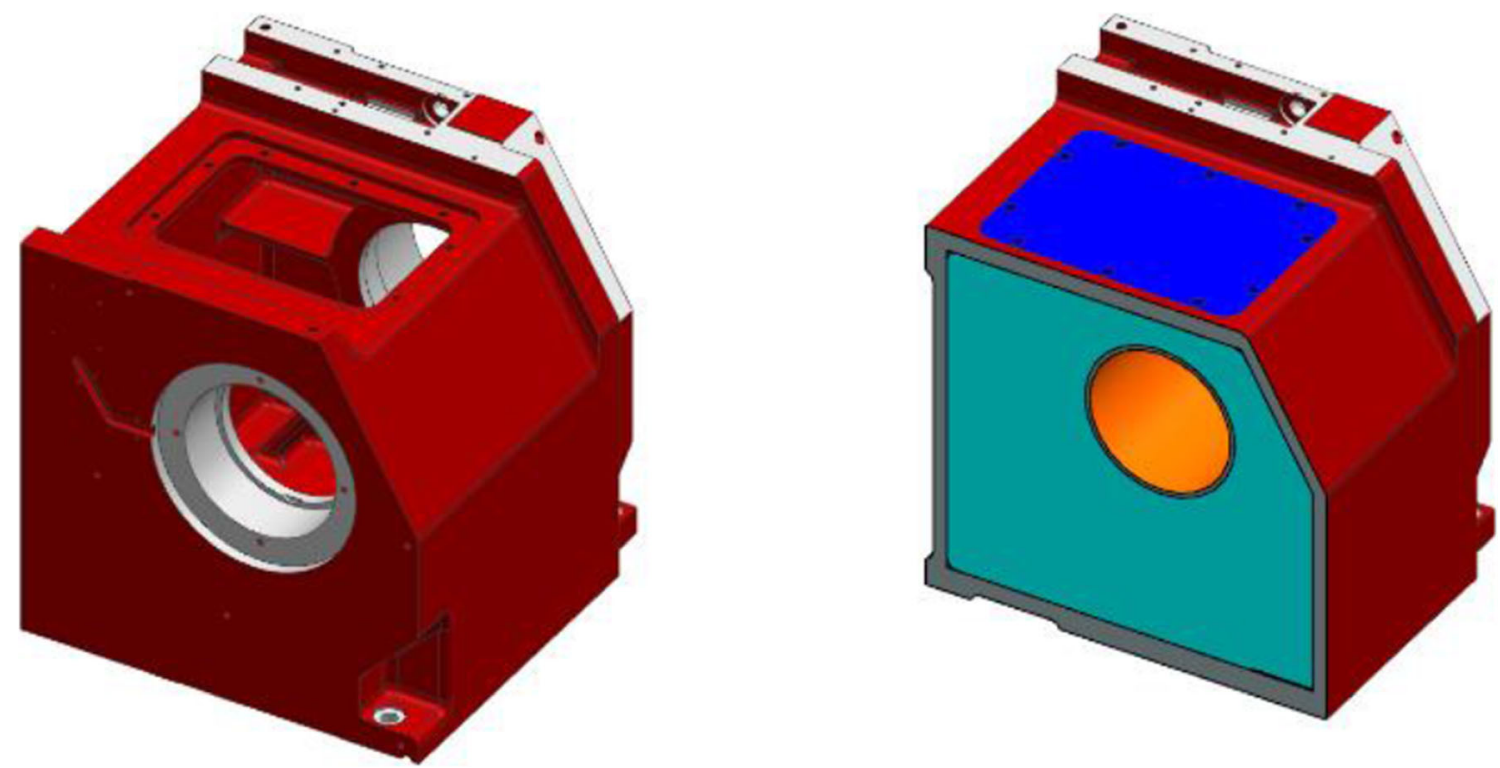

Fig. 31 Model of a spindle stock with highlighted cavity, which was filled with the GREC mixture 
Table 13 Modal properties of cast iron and hybrid spindle stock without connection interfaces

\begin{tabular}{|c|c|c|c|c|}
\hline \multirow{2}{*}{$\begin{array}{l}\text { Mode } \\
(-)\end{array}$} & \multicolumn{2}{|c|}{ Reference cast iron spindle stock } & \multicolumn{2}{|c|}{ Hybrid spindle stock with GREC filling } \\
\hline & $f(\mathrm{~Hz})$ & $\zeta(\%)$ & $f(\mathrm{~Hz})$ & $\zeta(\%)$ \\
\hline 1 & 966 & 0.18 & 1365 & 0.93 \\
\hline 2 & 1204 & 0.13 & 1574 & 0.83 \\
\hline 3 & 1245 & 0.10 & 1698 & 0.99 \\
\hline 4 & 1335 & 0.09 & 1784 & 0.58 \\
\hline 5 & 1438 & 0.18 & 1902 & 2.31 \\
\hline Average & & 0.15 & & 1.11 \\
\hline
\end{tabular}

of $1200 \mathrm{~kg} \mathrm{~m}^{-3}$ leads to a mass increase that cannot be neglected.

The application of the hybrid metal particle composites in machine tool structural parts confirmed the potential to improve the damping and dynamic stiffness of the parts. For the experiments without the connection interfaces, the damping of the rams increased from 0.1 to $0.24 \%$ when

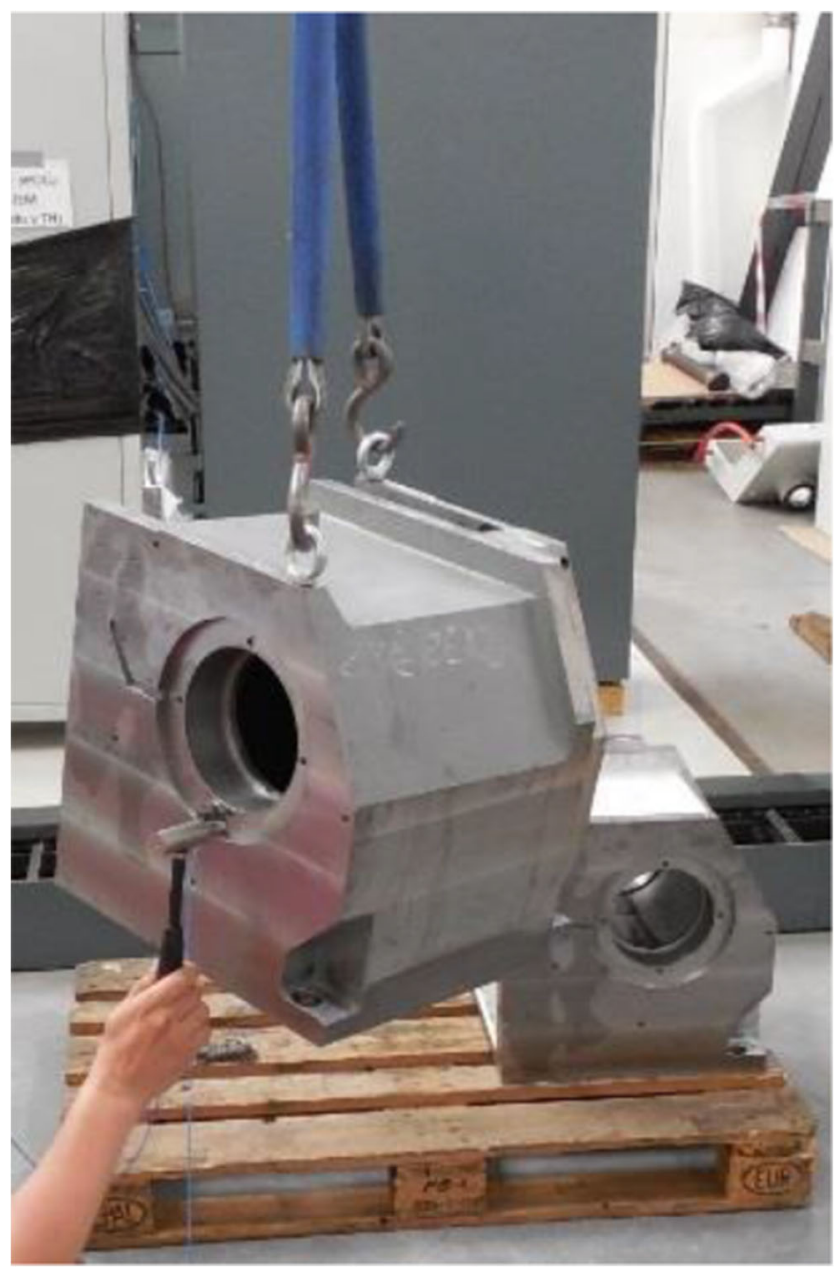

Fig. 32 Comparison of hybrid-cast iron spindle stock by experimental modal analysis the welded steel parts were tested to $0.42 \%$ for the hybrid structures with the GREC mixture and $0.92 \%$ for the REC mixture. Similar conclusions were obtained for the spindle stock, where the average damping increased from $0.15 \%$ for the cast iron stock to $1.1 \%$ for the hybrid cast iron composite stock.

The results show that although new structural part designs with new material structures can have significantly higher damping, static stiffness cannot be reduced if the focus remains on dynamic compliance and its minimization. Even significantly higher damping with slightly reduced static stiffness led to increased dynamic compliance in the assembly, which is undesirable behaviour for the sought-after machine tool productivity improvement.

For the structural parts, the hybrid structure application showed the potential to improve damping up to 10 times in comparison to the original metal parts. In the assemblies, where the connection interfaces provide most of the damping, the damping value was on a comparable level with the steel structures. In the lathe assembly, the tenfold higher damping of the hybrid spindle stock resulted in only a $7 \%$ change in the damping when replacing the original cast iron spindle stock.

\section{Discussion}

The presented experiments were focused on comparison of passive damping in hybrid design structures. Damping ratios for fundamental coupons, structural bodies and structural assemblies are presented. This approach identified the effect of connection interface damping.

Various coupons designed as hybrid structures were tested using experimental modal analysis. The experiment boundary conditions played an important role in the modal analysis measurement and subsequent damping evaluation. The experimental measurements could not be performed using identical boundary conditions for all coupons due to the wide range of material coupons and structural parts presented in the paper. The measurement boundary conditions were identical for the 


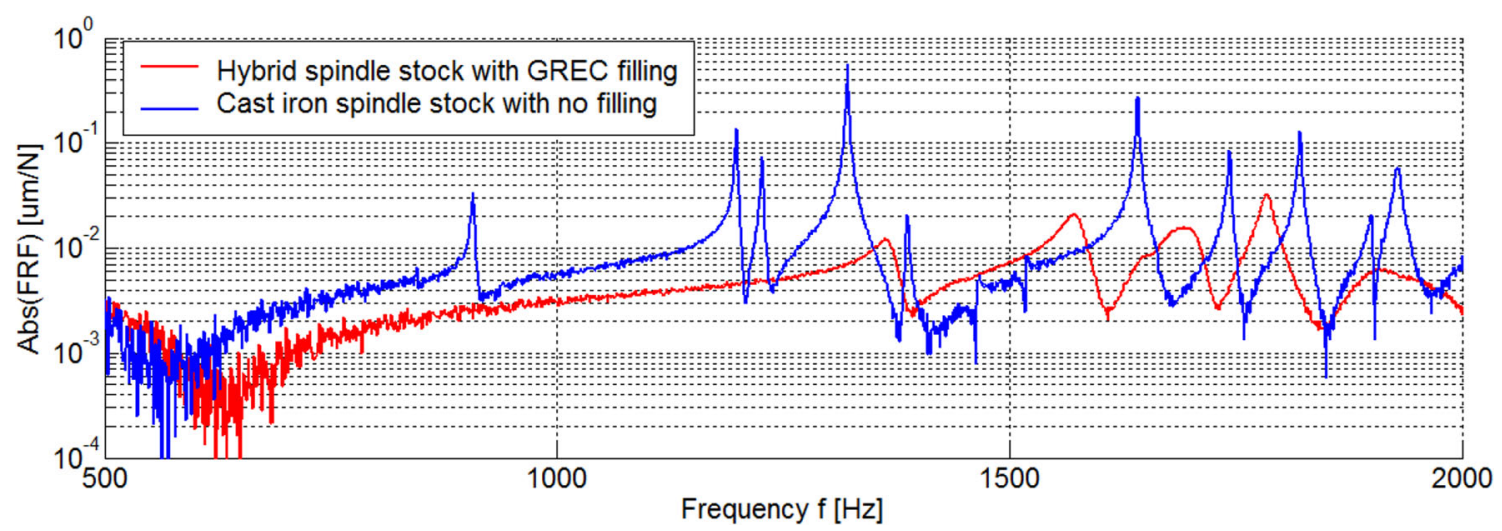

Fig. 33 Comparison of the frequency response function measured on two spindle stock variants

same group of tested coupons or structural parts. Therefore, in each group of tested coupons or parts, the change in damping ratio could be directly evaluated when the reference metal part and new hybrid metal-composite part design were compared.

Two types of hybrid material structure designs were tested. Both particle composites and fibre composites demonstrated the capability to increase the damping ratio for fundamental material coupons and single structural parts in the free-free conditions.

The particle composite mixtures, while having a damping ratio almost two orders higher than steel, achieved an average damping ratio in the range of $0.4-$ $1.1 \%$ in the three tested structural parts, while the reference steel parts were tested with damping ratios of $0.1-$ $0.24 \%$ when welded steel structures were tested, and a damping ratio of $0.15 \%$ when the cast iron stock was tested. Therefore, it was possible to improve damping two to fourfold or even more in comparison with the reference metal design. For the fibre composites, damping of hybrid structural parts was improved two to threefold when the stand-alone configuration was tested.

In the assembly, an additional damping of connection interfaces between the structural parts came into importance. The overall damping ratio significant improvement on the hybrid structure damping increase was not detected comparing to the reference steel or cast iron design. The assembly behaviour did not seem to be influenced by

Table 14 Modal properties of cast iron and hybrid spindle stock without connection interfaces

\begin{tabular}{lllllll}
\hline \multicolumn{2}{l}{ Reference spindle stock } & & \multicolumn{3}{l}{ Hybrid spindle stock } \\
\cline { 1 - 1 } \cline { 6 - 7 } & $\zeta(\%)$ & $|\mathrm{H}|(\mathrm{um} / \mathrm{N})$ & & $f(\mathrm{~Hz})$ & $\zeta(\%)$ & $|\mathrm{H}|(\mathrm{um} / \mathrm{N})$ \\
\hline 325 & 2.09 & 0.13 & & 327 & 2.24 & 0.11 \\
\hline
\end{tabular}

structural part damping. The damping ratio of the most important mode shapes did not show any tendency to improve, although the structural part had a major influence on the dominant mode shapes which were evaluated. Often, the damping ratio in the assembly with a hybrid structural part, which had higher damping on the body level, was smaller than in the assembly with a reference steel or cast iron structural part. This reduction in damping went hand in hand with an increase in dynamic compliance for the assembly with the hybrid structural part and was also connected to changes in the static stiffness of the part and assembly.

The final dynamic compliance was higher for the structural parts with higher damping and lower static stiffness than for the reference body with lower damping and higher static stiffness. This result was probably to be expected and contests the idea of designing new lightweight structural machine tool parts with lower mass and static

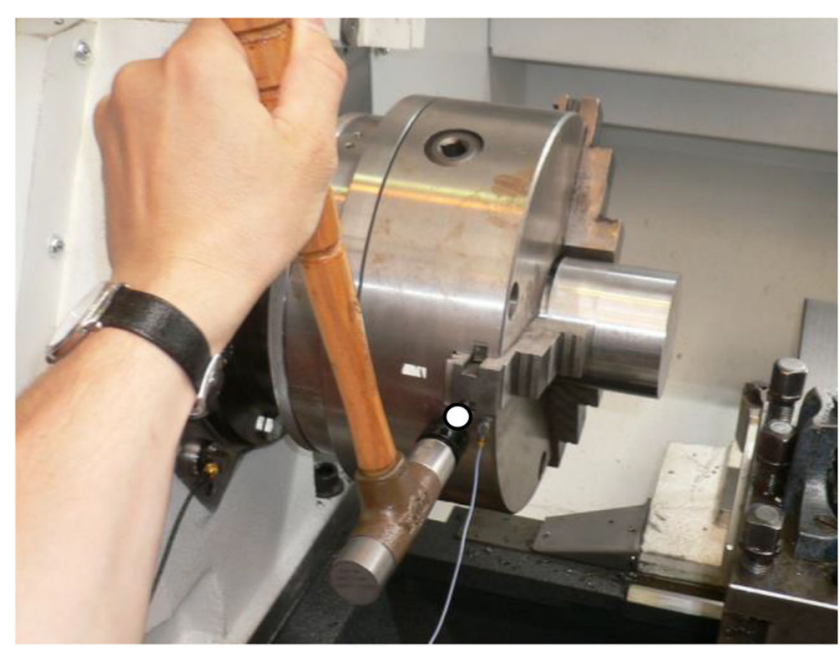

Fig. 34 Experimental modal analysis on lathe with hybrid spindle stock: excitation and response on the chuck 


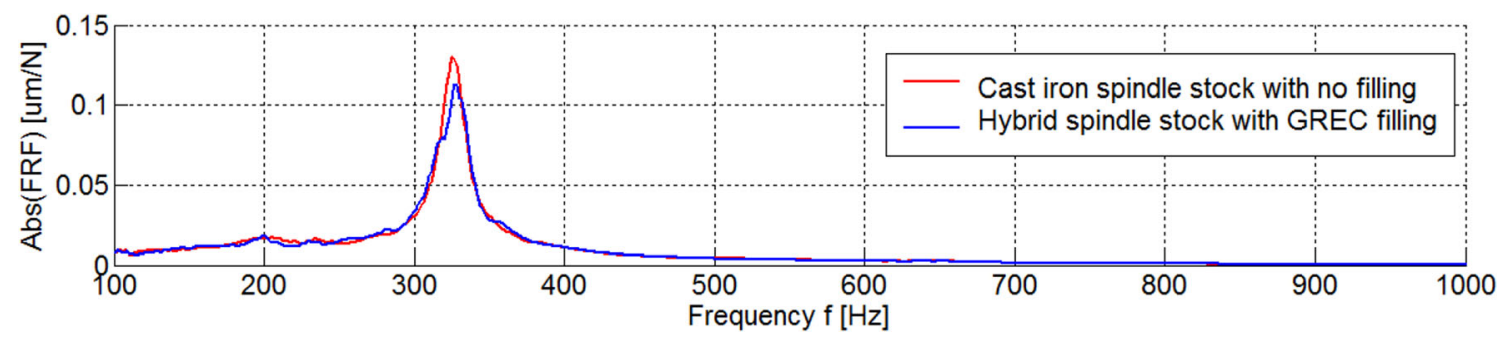

Fig. 35 Comparison of dynamic compliance measured at the lathe chuck for assemblies with the cast iron spindle stock or the hybrid spindle stock

stiffness which would be compensated by significantly improved damping. As the results showed, the static stiffness reduction always led to a dynamic compliance increase, regardless of how part damping changed. On the other hand, in one of the tested cases, even the improved static stiffness of a hybrid part along with improved damping did not result in any dynamic compliance reduction.

A machine tool assembly presents a complex chain of parts and their connection interfaces. Any one of the components could present a weak link in terms of dynamic behaviour, and improved dynamic behaviour of a single part may not always result in the dynamic improvement of the whole assembly, as another weak link in the design could occur and negate the changes in the behaviour due to mass and stiffness changes of a single part. Due to its complexity, improving machine tool behaviour just by improving the dynamic behaviour of a single part is not an optimal approach.

\section{Conclusions}

Case studies in the application of composite materials into hybrid designs of machine tool structural parts were performed with a focus on improving damping of structural parts and machine tool assemblies. Experimental modal analysis (EMA) was used as the main approach for identification of the damping ratio on a basic coupon level, structural part level and structural assembly level. The EMA enabled to compare the damping potential of the hybrid part design with respect to the complete assembly structure behaviour. Both particle composites and fibre composites were successful in improving the damping ratio of single parts, but the results did not improve when the hybrid part was mounted into an assembly. The main reason is that the damping of the connection interfaces has in the assembled structure higher significance than structural damping of single part bodies. We can see that improved material damping is not the main effect of the hybrid design for
Table 15 Proportion of damping ratios: hybrid material coupons vs. iron-based coupons

\begin{tabular}{llll}
\hline & & $\begin{array}{l}\text { Average } \\
\text { damping }(\%)\end{array}$ & $\begin{array}{l}\text { Ratio hybrid vs. } \\
\text { iron-based }\end{array}$ \\
\hline Elementary coupons & Steel coupon with no filling & 0.03 & \\
(Table 9) & Steel coupon with GREC filling & 0.31 & 10.33 \\
& Steel coupon with REC filling & 2.73 & 91.00 \\
Stand-alone slender ram & Original steel ram & 0.09 & \\
(Table 11) & Modified steel ram with no filling & 0.24 & 2.67 \\
& Modified steel ram with REC filling & 0.92 & 10.22 \\
& Modified steel ram with GREC filling & 0.45 & 5.00 \\
Slender ram in assembly & Original steel ram & 0.83 & 1.49 \\
(Table 12) & Modified steel ram with no filling & 1.24 & 1.51 \\
& Modified steel ram with REC filling & 1.25 & 1.82 \\
Stand-alone spindle stock & Modified steel ram with GREC filling & 1.51 & \\
(Table 13) & Original cast iron spindle stock & 0.15 & 7.40 \\
Spindle stock in assembly & Hybrid spindle stock with GREC filling & 1.11 & \\
(Table 14) & Original cast iron spindle stock & 2.09 & 1.07 \\
\hline
\end{tabular}




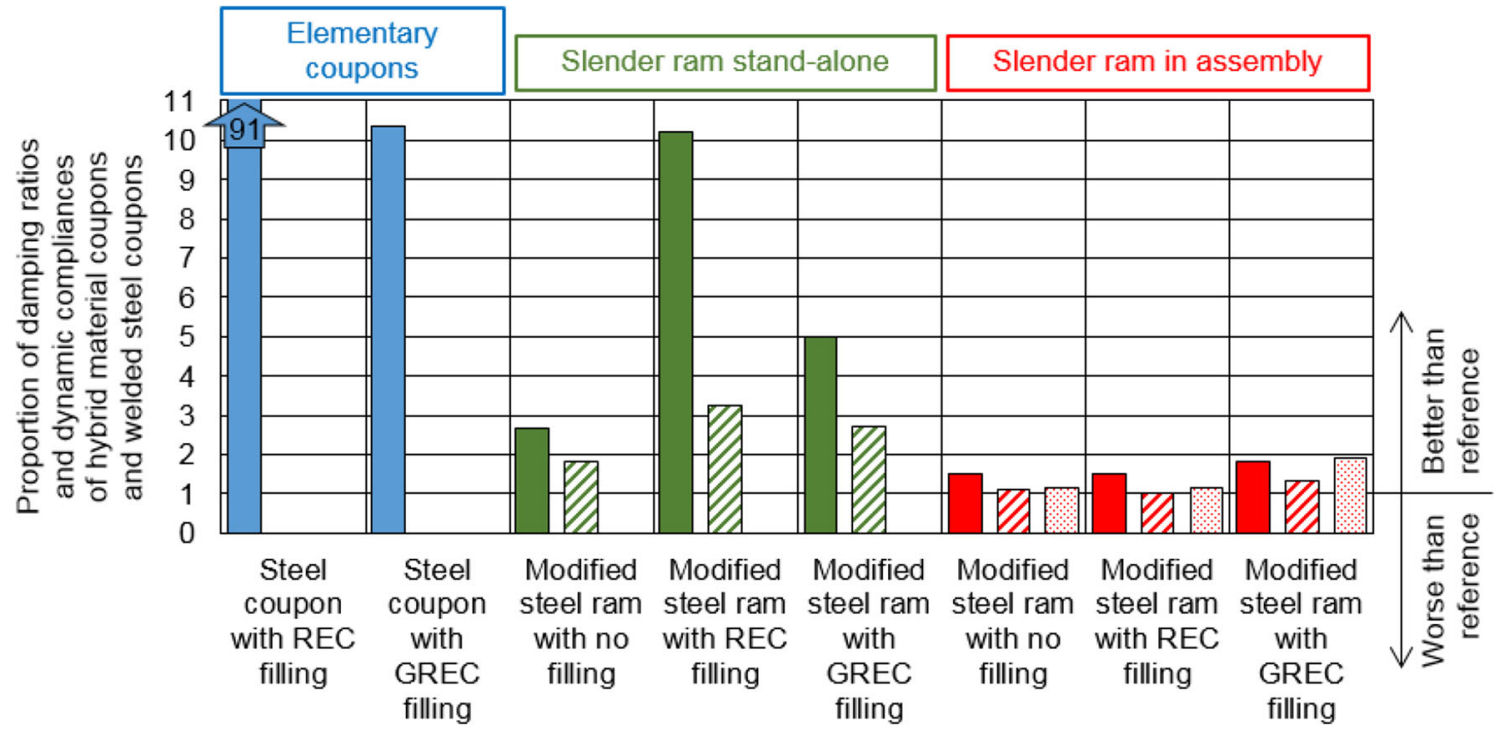

Fig. 36 Proportion of damping ratios (solid colour bars, hybrid material coupons vs. welded steel coupons) and dynamic compliance on critical Eigenfrequency (hatched colour bars mean vertical direction, dotted

colour bars mean horizontal direction, welded steel coupons vs. hybrid material coupons) for the slender ram demonstration part. Higher values indicate better relative results

decreasing the dynamic compliance of the structure. The important benefit should be potential of the lightweight design.

The lightweight design of machine tools is beneficial. But it must be performed without static stiffness reduction when using traditional machine tool design. Fibre composites can help with mass reduction if hybrid stiffness is designed to sufficient static stiffness values. Particle composites, which were discussed in the paper, could provide lightweight design options only if the original metal base part is redesigned. The ribs are removed and the skin vibrations are suppressed by the particle composite. The total weight is reduced.
The tested application was focused on motion axis components, which play a significant role in machine tool dynamic behaviour. The effect of improved structural part damping was not detected through the improvement of the machine tool dynamic behaviour improvement. For the hybrid material application to the non-movable body of a machine tool assembly, $100 \%$ improvement of damping along with a 17 to $30 \%$ increase in the static stiffness of a lathe spindle stock resulted in only a $7 \%$ reduction in the dynamic compliance of the lathe assembly. These results subsequently mean that it is also important to focus on the damping of the interfaces during the machine tool design e.g. application of the sliding guideways or the hydrostatic guideways.
Fig. 37 Proportion of damping ratios (solid colour bars, hybrid material coupons vs. cast iron coupons) and dynamic compliance on critical Eigenfrequency (hatched colour bars, cast iron coupons vs. hybrid material coupons) for the bulk spindle stock demonstration part. Higher values indicate better relative results

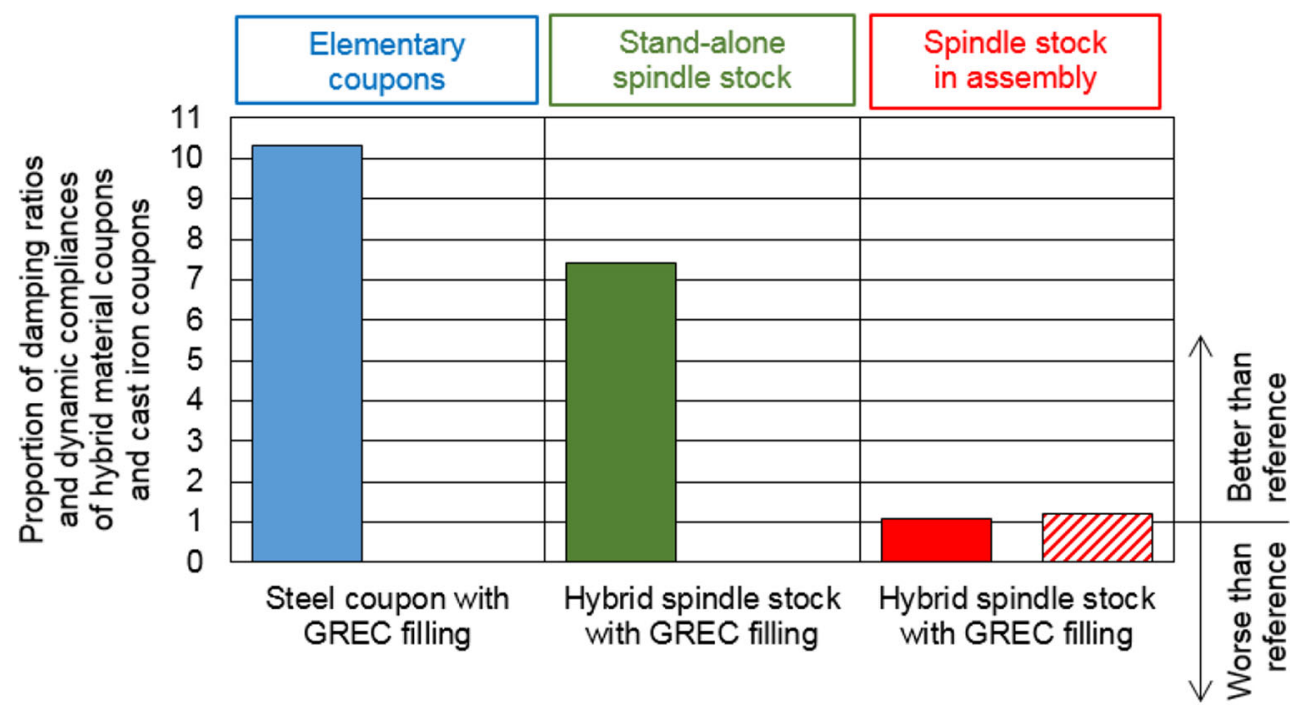


Author contribution Viktor Kulíšek contributed to experiments, evaluated experimental results and wrote the manuscript. Petr Kolar contributed to the experiments evaluation, paper concept and writing. Pavel Vrba contributed to experimental work and result discussion. Jan Smolík contributed to hybrid coupons concept, experiment conception and data evaluation. Miroslav Janota contributed to experiment measurement, results evaluation, paper concept and writing. Milan Růžička contributed to the paper concept and helped with constructive discussions. Martin Machálka contributed to the design of coupons and results evaluation.

Funding The authors would like to acknowledge funding support from the Czech Ministry of Education, Youth and Sports under the project CZ.02.1.01/0.0/0.0/16_026/0008404 "Manufacturing Technology and Precision Engineering". This work was also supported by the Grant Agency of the Czech Technical University in Prague, grant no. SGS19/ $165 / \mathrm{OHK} 2 / 3 \mathrm{~T} / 12$. The project is also co-financed by the European Union. Support from the companies BRAY, KOVOSVIT MAS and TAJMAC-ZPS for the experiments is also gratefully acknowledged.

\section{Availability of data and material Not applicable}

Code availability Not applicable

\section{Declarations}

Ethics approval Not applicable

Consent to participate Not applicable

Consent for publication Not applicable

Conflict of interest The authors declare that they have no competing interests

\section{References}

1. Tlusty J, Polacek M (1957) Beispiele der behandlung der selbsterregten Schwingung der Werkzeugmaschinen. FoKoMa, Hanser Verlag, Munchen

2. Altintas Y, Weck M (2004) Chatter stability of metal cutting and grinding. CIRP Ann 53(2):619-642. https://doi.org/10.1016/ S0007-8506(07)60032-8

3. Munoa J, Beudaert X, Dombovari Z, Altintas Y, Budak E, Brecher C, Stepan AG (2016) Chatter suppression techniques in metal cutting. CIRP Ann 65(2):785-808. https://doi.org/10.1016/j.cirp. 2016.06.004

4. Kolar P, Sulitka M, Šindler J (2014) Development methods for high performance machine tools. In: Proceedings of 2. Wiener Produktionstechnik Kongress - WPK 2014. Vienna, Austria, pp 333-342 ISBN 978-3-903015-00-5

5. Zulaika JM, Valente A, Dhokia V (2015) Dematerialized manufacturing systems. Int J Computer Integrated Manufacturing 28(4):337-338. https://doi.org/10.1080/0951192X.2015.1016365

6. Möhring H-C, Brecher C, Abele E et al (2015) Materials in machine tools structures. CIRP Ann Manuf Technol 64(2):725-748. ISSN 0007-8506. [13 December 2016]. https://doi.org/10.1016/j.cirp. 2015.05.005

7. Neugebauer R, Denkena B, Wegener K (2017) Mechatronic systems for machine tools. CIRP Ann Manuf Technol 56(2):657-686. https://doi.org/10.1016/j.cirp.2007.10.007
8. Vlacil J, Rebelein C, Zaeh M (2016) The effect of the feed drive control on the damping of structural vibrations of machine. In: Proceedings of Thirteenth International Conference on HIGH SPEED MACHINING 2016 - HSM 2016. 4th October 2016, Metz, France.

9. Beudaert X Mancisidor I Ruiz LM, Barrios A Erkorkmaz K, Munoa J (2016) Analysis of the feed drives control parameters on structural chatter vibrations. In: Proceedings of Thirteenth International Conference on HIGH SPEED MACHINING 2016 HSM 2016. 4th October 2016, Metz, France. Open access available on-line: https://hal.archives-ouvertes.fr/hal-01484796/document

10. Kroll L, Blau P, Wabner M, Friess U, Eulitz J, Klärner M (2011) Lightweight components for energy-efficient machine tools. CIRP J Manuf Sci Technol 4(2):148-160

11. Möhring H-C (2017) Composites in production machines. In: Procedia CIRP 2017, vol 66, pp 2-9. https://doi.org/10.1016/j. procir.2017.04.013

12. Kono D, Mizuno S, Muraki T, Nakanami M (2019) A machine tool motorized spindle with hybrid structure of steel and carbon fiber composite. CIRP Ann Manuf Technol 68:389-392. https://doi.org/ 10.1016/j.cirp.2019.04.022

13. Suh JD, Chang SH, Lee DG et al (2001) Damping characteristics of composite hybrid spindle covers for high speed machine tools. J Mater Proc Technol 113(1-3):178-183 ISSN 0924-0136

14. Lee DG, Chang SH, Kim HS (1998) Damping improvement of machine tool columns with polymer matrix fiber composite material. Compos Struct 43(2):155-163 ISSN 0263-8223

15. Chang SH, Kim PJ, Lee DG, Choi JK (2001) Steel-composite hybrid headstock for high-precision grinding machines. Compos Struct 53(1):1-8 ISSN 0263-8223

16. Cho SK, Kim HJ, Chang SH (2011) The application of polymer composites to the table-top machine tool components for higher stiffness and reduced weight. Compos Struct 93(2):492-501 ISSN $0263-8223$

17. Lee DG, Suh JD, Kim HS, Kim JM (2004) Design and manufacture of composite high speed machine tool structures. Compos Sci Technol 64(10-11):1523-1530. ISSN 0266-3538. [20 March 2011]. https://doi.org/10.1016/j.compscitech.2003.10.021

18. Neugebauer R, Hipke T (2006) Machine tools with metal foam. Adv Eng Mater 8(9):858-863. ISSN: 1527-2648. [20 March 2011]. https://doi.org/10.1002/adem.200600095

19. Smolik J, Kulisek V (2009) Application of unconventional materials on primary structural parts of machine tools. J Mach Eng 9(2): 93-105 ISSN: 1895-7595

20. Smolik J, Kulisek V, Janota M (2011) Application of sandwichbased designs on main structural parts of machine tools. In: Proceedings of the 6th ASME 2011, International Manufacturing Science and Engineering Conference. MSEC, June 13-17, Corvallis, Oregon, USA. p. 69-78. ISBN: 978-0-7918-4431-1.

21. Aggogeri F, Borboni A, Merlo et al (2017) Vibration damping analysis of lightweight structures in machine tools. Materials. https://doi.org/10.3390/ma10030297

22. Kepczak N (2019) Influence of the addition of styrene-butadiene rubber on the dynamic properties of polymer concrete for machine tool applications. Adv Mechan Eng 11(7):1-11. https://doi.org/10. $1177 / 168714019865841$

23. Allemang RJ, et al (1998) Vibrations: analytical and experimental modal analysis, UC-SDRL-CN-20-263-662, $160 \mathrm{pp}$.

24. Allemang RJ, et al (1999) Vibrations: experimental modal analysis, UC-SDRL-CN-20-263-663/664, 250 pp.

25. Richardson MH, Formenti DL (1982) Parameter estimation from frequency response measurements using rational fraction polynomials. In: Proceedings of the 1st International Modal Analysis Conference, pp 167-181

26. Smith S, Bilbao-Ludena JC, Catalfamo S, Brake MRW, Reuss P, Schwingshackl CW (2016) The effects of boundary conditions, 
measurement techniques, and excitation type on measurements of the properties of mechanical joints. In: Kerschen G (ed) Nonlinear Dynamics, vol 1. Springer International Publishing, Cham, pp 415431. [Internet]; [cited $2018 \mathrm{Dec} 9$ ]. Available from:. https://doi.org/ 10.1007/978-3-319-15221-9 36

27. Carne T.G., Clark R. Dohmann. Support conditions, their effect on measured modal parameters. In: Proceedings of Fifth International Conference on Sound and Vibration [Internet]. Adelaide, South Australia: The International Institute of Acoustics and Vibration; 1997. p. 8. Available from: https://www.acoustics.asn.au/ conference proceedings/ICSVS-1997/pdf/scan/sv970505.pdf

28. Weck M Handbook of machine tools. Wiley, New York c1984. ISBN 978-0471262268

29. Tlusty J Manufacturing processes and equipment. Prentice-Hall, Upper Saddle River, NJ c2000. ISBN 978-0201498653

30. Yakout M, Elkhatib A, Nassef MGA (2018) Rolling element bearings absolute life prediction using modal analysis. J Mech Sci Technol 32:91-99. https://doi.org/10.1007/s12206-017-1210-1

31. El-Labban H, Abdelaziz M, Yakout M, Elkhatib A (2013) Prediction of mechanical properties of nano-composites using vibration modal analysis: application to aluminum piston alloys. Mater Perform Charac 2(1):454-467. https://doi.org/10.1520/ MPC20130006

32. Chang K-C, Kim C-W (2016) Modal-parameter identification and vibration-based damage detection of a damaged steel truss bridge. Eng Struct 122:156-173

33. Özsahin O, Altintas Y (2015) Prediction of frequency response function (FRF) of asymmetric tools from the analytical coupling of spindle and beam models of holder and tool. Int J Mach Tools Manuf 92:31-40
34. Yakout M, Nassef MGA, Backar S (2019) Effect of clearances in rolling element bearings on their dynamic performance, quality and operating life. J Mech Sci Technol 33:2037-2042. https://doi.org/ 10.1007/s12206-019-0406-y

35. Huo D, Cheng K, Wardle F (2010) A holistic integrated dynamic design and modelling approach applied to the development of ultraprecision micro-milling machines. Int $\mathrm{J}$ Mach Tools Manuf 50(4):335-343

36. Zaeh MF, Rebelein C, Semm T (2019) Predictive simulation of damping effects in machine tools. CIRP Ann Manuf Technol 69: 393-396

37. Semm T, Rebelein C, Zaeh MF (2019) Prediction of the position dependent dynamic behavior of a machine tool considering local damping effects. CIRP J Manuf Sci Technol 27:68-77

38. SEMM T, Spannagl MF, Zaeh MF (2018) Dynamic substructuring of machine tools considering local damping models. In. $8^{\text {th }}$ CIRP Conference on High Performance Cutting. Procedia CIRP 77:670 674

39. Semm T, Nierlich MB, Zaeh MF (2019) Substructure coupling of machine tool in arbitrary axis positions considering local linear damping models. J Manuf Sci Eng:141

40. Rebelein C, Vlacil J, Zaeh MF (2017) Modeling of the dynamic behaviour of machine tools: influences of damping, friction, control and motion. Prod Eng Res Devel 11:61-74

41. Brecher C, Fey M (2013) Baumler, S. Damping models for machine tool components of linear axes. CIRP Ann Manuf Technol $62: 399-402$

Publisher's note Springer Nature remains neutral with regard to jurisdictional claims in published maps and institutional affiliations. 